\title{
The Impact of Crystal Structure and Molecular Conformation on the Hydration Kinetics of Fluconazole
}

DOI:

10.1021/acs.cgd.9b01066

\section{Document Version}

Accepted author manuscript

Link to publication record in Manchester Research Explorer

\section{Citation for published version (APA):}

Basford, P., Back, K. R., Cram, M., Docherty, R., Davey, R. J., \& Cruz-cabeza, A. J. (2019). The Impact of Crystal Structure and Molecular Conformation on the Hydration Kinetics of Fluconazole. Crystal Growth \& Design. https://doi.org/10.1021/acs.cgd.9b01066

\section{Published in:}

Crystal Growth \& Design

\section{Citing this paper}

Please note that where the full-text provided on Manchester Research Explorer is the Author Accepted Manuscript or Proof version this may differ from the final Published version. If citing, it is advised that you check and use the publisher's definitive version.

\section{General rights}

Copyright and moral rights for the publications made accessible in the Research Explorer are retained by the authors and/or other copyright owners and it is a condition of accessing publications that users recognise and abide by the legal requirements associated with these rights.

\section{Takedown policy}

If you believe that this document breaches copyright please refer to the University of Manchester's Takedown Procedures [http://man.ac.uk/04Y6Bo] or contact uml.scholarlycommunications@manchester.ac.uk providing relevant details, so we can investigate your claim.

\section{OPEN ACCESS}




\title{
The Impact of Crystal Structure and Molecular Conformation on the Hydration Kinetics of Fluconazole
}

\author{
Patricia A. Basford, ${ }^{\text {ab* }}$ Kevin R. Back, ${ }^{a}$ Michael Cram, ${ }^{a}$ Robert Docherty, ${ }^{\text {a }}$ Roger J. Davey ${ }^{\mathrm{b}}$ and Aurora \\ J. Cruz-Cabeza. ${ }^{\text {** }}$ \\ ${ }^{a}$ Medicinal Sciences, Pfizer R\&D UK Ltd, Sandwich, CT13 9ND (UK) \\ ${ }^{\mathrm{b}}$ School of Chemical Engineering and Analytical Science, University of Manchester, Manchester, M13 9PL (UK)
}

Supporting Information Placeholder

\begin{abstract}
In this contribution the hydration kinetics of three anhydrous polymorphs (AH-A, AH-B and AH-C) of fluconazole [2-(2,4-difluorophenyl)-1,3-bis ( $1 H$ - 1,2,4-triazol-1-yl)-propan-2ol] were studied. The conversion kinetics from the anhydrous forms to the monohydrate $(\mathrm{MH})$ were monitored at various relative humidities above the critical water activity. The studies revealed very different kinetic stabilities for the three anhydrous forms, with $\mathrm{AH}-\mathrm{A}$ and $\mathrm{AH}-\mathrm{C}$ converting much more easily to the $\mathrm{MH}$ than AH-B. Various energetic factors, which may be influencing the kinetics of hydration, were explored together with crystal structure and molecular conformation similarities between the anhydrous forms and the $\mathrm{MH}$. The level of conformational and packing similarity between the anhydrous and $\mathrm{MH}$ structures was found to be consistent with the ease of hydration. We believe that surface similarity may be required for the nucleation of the hydrate, whilst the level of crystal packing similarity impacts the ease of growth. In terms of conformational variations, AH-B was found to require a significantly more dramatic conformational change to convert to the $\mathrm{MH}$ conformation than those in either $\mathrm{AH}-\mathrm{A}$ or AH-C. Soft planes (low attachment energies) may allow for easier diffusion of solvent into the crystal structure to allow for solvation. The overall kinetic energy barrier of water diffusion into the lattice plus conformational change was found to correlate well with our observed hydration kinetics, indicating that both the crystal structure and the conformation play a role in the kinetic stability towards hydration of the various fluconazole polymorphs.
\end{abstract}

\section{INTRODUCTION}

In drug delivery, Active Pharmaceutical Ingredients (APIs) are most commonly administered as crystalline solids, formulated as a solid dosage form, such as a tablet. Crystallisation provides options to purify and control the properties of the API, such as particle size or shape. ${ }^{1}$ A crystalline state usually provides improved physical and chemical stability over the amorphous state, which may then facilitate an acceptable shelf-life for the API and resultant solid dosage form.

A thorough understanding of the solid form landscape is a critical activity in the development of a drug product. Polymorphism is a well-known phenomenon, with the API crystallising in more than one distinguishable crystal structure, each with identical chemical composition. ${ }^{2}$ The term solvate is used when a solvent molecule, in addition to the drug molecule, becomes an integral part of the crystal lattice. ${ }^{3-4}$ When the crystal structure incorporates water the term hydrate is used, this representing by far the most common type of solvate. ${ }^{5}$

The physicochemical properties of a material may affect the manufacturability and stability of the API and drug product. ${ }^{6}$ Many physicochemical properties are related to the crystal structure and therefore a phase conversion to a hydrate has the ability to impact the properties of the drug product such as stability, dissolution, and bioavailability, potentially compromising the drug effectiveness. In general, the formation of a hydrate lowers solubility, ${ }^{7}$ increasing the risk that hydration will negatively impact bioavailability. As a consequence, the Food and Drug Administration recommends that hydrate formation and its effect on the drug product properties should be understood; ${ }^{8}$ this includes identification of any hydrated forms. ${ }^{9}$

The occurrence of hydrates is thought to be common, being a reported feature of approximately one in three pharmaceutical compounds. ${ }^{10}$ Since water is frequently present within the manufacturing process, e.g., as atmospheric water, via excipients or aqueous processes such as wet granulation ${ }^{11}$ and tablet coating. There is a preference to avoid forms presenting a risk of hydrate formation. This is often achieved via salt or co-crystal design; however, it is not always possible to identify alternative solid forms with acceptable properties. In these cases, it is critical to understand the thermodynamic ${ }^{12-15}$ and kinetic stability ${ }^{16-18}$ of both the anhydrous and hydrated forms with respect to water activity and temperature.

Once the API has been formulated, hydration will likely require a solid-state conversion and the mechanism for this conversion may provide a kinetic barrier to hydration. Many studies to date have focused on channel hydrates ${ }^{19-23}$ where there is little barrier to hydration, the hydrate having a similar crystal structure to the anhydrous form. Here we study a more complex system where hydration requires structural rearrangement. ${ }^{24-25}$

Fluconazole [2-(2,4-difluorophenyl)-1,3-bis ( $1 \mathrm{H}$ - 1,2,4-triazol1 -yl)-propan-2-ol] is a flexible drug compound used in the systemic treatment of fungal infections. This drug is on the World Health Organisation list of essential medicines. Its molecular structure (Figure 1) has been described here relative to the central, tetrahedral $\mathrm{C} 12$. Four distinct groups are bonded to $\mathrm{C} 12$ : a diflurophenyl ring, a hydroxyl group and two identical $-\mathrm{CH}_{2}-$ triazole groups. Despite its relatively small molecular size (22 heavy atoms only), fluconazole is highly flexible with six rotatable bonds defining its molecular conformation. 
Multiple polymorphic forms of fluconazole have been reported in the literature, ${ }^{26-31}$ as well as various solvates ${ }^{32}$ and a monohydrate. ${ }^{33}$ Here, we study the hydration behaviour of three fluconazole polymorphs to the monohydrate form; how particle size reduction and seed addition may influence the hydration kinetics. We put special emphasis on understanding how polymorphic changes in molecular conformations and crystal packing impact the kinetics of hydration of this important antifungal drug.

Since there is some variability in the naming convention of fluconazole polymorphs within the literature, we have summarised the crystallographic information for the forms studied here in Table 1 together with their Cambridge Structural Database ${ }^{34}$ (CSD) refcode and our adopted naming. We have used the following nomenclature throughout this contribution: $\mathrm{MH}$ for the monohydrate form (IVUQIZ), AH-A (Anhydrous-A) for the triclinic polymorph (IVUQOF), AH-B for the $\mathrm{P} 21 / \mathrm{n}$ polymorph (IVUQOF01) and AH-C for the $Z^{\prime}=1$ Pbca polymorph (IVUQOF02).

Table 1 Summary of the crystallographic information, naming and CSD refcode for the polymorphic and monohydrate forms of fluconazole studied.*

\begin{tabular}{|c|c|c|c|c|}
\hline Form & МH & AH-A & AH-B & AH-C \\
\hline CSD Refcode & IVUQIZ $^{32}$ & IVUQOF $^{32}$ & IVUQOF01 $1^{30}$ & IVUQOF02 $2^{30}$ \\
\hline Crystal system & triclinic & triclinic & monoclinic & orthorhombic \\
\hline Space group & $P \overline{1}$ & $P \overline{1}$ & $P 2_{1} / \mathrm{n}$ & Pbca \\
\hline $\mathrm{a}(\AA)$ & $5.626(10)$ & $7.499(10)$ & $6.699(4)$ & $12.9282(9)$ \\
\hline $\mathrm{b}(\AA)$ & $11.737(2)$ & $7.787(10)$ & $27.387(19)$ & $6.0241(5)$ \\
\hline $\mathrm{c}(\AA)$ & $12.306(3)$ & $11.982(2)$ & $15.290(11)$ & $34.834(3)$ \\
\hline$\alpha\left(^{\circ}\right)$ & $71.24(10)$ & $84.95(10)$ & 90 & 90 \\
\hline$\beta\left(^{\circ}\right)$ & $79.87(10)$ & $84.63(10)$ & $90.32(3)$ & 90 \\
\hline$\gamma\left({ }^{\circ}\right)$ & $84.38(10)$ & $75.89(10)$ & 90 & 90 \\
\hline Volume $\left(\AA^{3}\right)$ & 756.68 & 674.05 & 2805.09 & 2712.9 \\
\hline Packing coefficient & 0.664 & 0.700 & 0.677 & 0.697 \\
\hline Density & 1.423 & 1.509 & 1.45 & 1.5 \\
\hline $\mathrm{Z}$ & 2 & 2 & 8 & 8 \\
\hline$Z^{\prime}$ & 1 & 1 & 2 & 1 \\
\hline $\mathrm{T}(\mathrm{K})$ & $283-303$ & 193 & 100 & 100 \\
\hline R-Factor (\%) & 4.29 & 3.50 & 3.46 & 6.96 \\
\hline
\end{tabular}

*Monohydrate (MH), Anhydrous-A (AH-A), Anhydrous-B (AH-B) and Anhydrous-C (AH-C); a form nomenclature has not been assigned to other anhydrous polymorphs found in the CSD; IVUQOF03 and IVUQOF04 as these forms were not experimentally accessible.

For AH-A and AH-C, The CSD structure is recorded at sub-ambient conditions, in conformation of the prepared solid form an equivalent room temperature structure was used to simulate the pXRD patterns (see section 3 of the Supporting Information).

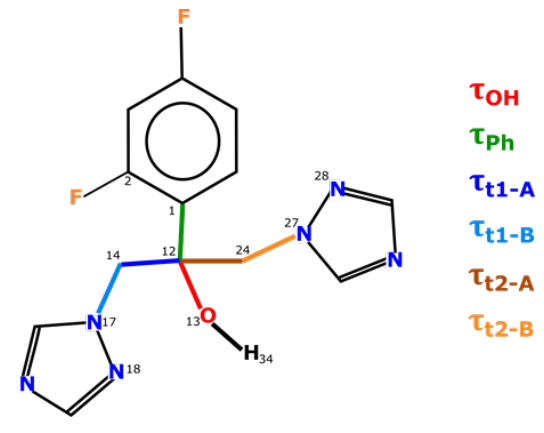

Figure 1 Molecular structure of fluconazole with atom numbering and definition of its six rotatable bonds.

\section{METHODS}

\subsection{Materials}

Fluconazole was gifted by Pfizer Global Supply, Ringaskiddy, Ireland. The various forms were first produced as pure samples in small quantities. Following this, larger batches of the various forms were prepared via seeded crystallisations.
For the synthesis of the seeds: MH, Fluconazole $(200 \mathrm{mg} / \mathrm{mL})$ was dissolved in ethanol: water $(3: 1 \mathrm{v} / \mathrm{v})$ at $70{ }^{\circ} \mathrm{C}$ and the solution was then cooled to $10{ }^{\circ} \mathrm{C}$ at $2{ }^{\circ} \mathrm{C} / \mathrm{min}$. AH-A, Fluconazole $(110$ $\mathrm{mg} / \mathrm{mL}$ ) was dissolved in anhydrous propan-2-ol at $70{ }^{\circ} \mathrm{C}$ and the solution was then cooled to $10^{\circ} \mathrm{C}$ at $2{ }^{\circ} \mathrm{C} / \mathrm{min}$. AH-B, A saturated solution containing $\mathrm{MH}$ and $\mathrm{AH}-\mathrm{A}(1: 1 \mathrm{w} / \mathrm{w})$ was agitated in anhydrous butan-2-one for 7 days until pure AH-B crystals were obtained. AH-C, Fluconazole MH was dried under vacuum (50 mbar) at $70^{\circ} \mathrm{C}$.

The seeds were confirmed to be phase pure by comparison of experimental and simulated powder X-ray diffraction patterns (see section 3 of the Supporting Information) and were then used in the preparation of larger scale batches of the various forms $(8-10 \mathrm{~g})$. For the MH, Fluconazole $(200 \mathrm{mg} / \mathrm{mL})$ was dissolved in ethanol: water $(1: 1 \mathrm{v} / \mathrm{v})$ at $70{ }^{\circ} \mathrm{C}$, the solution was cooled to $50{ }^{\circ} \mathrm{C}$ at 1 ${ }^{\circ} \mathrm{C} / \mathrm{min}$ and seeded with $\mathrm{MH}(1 \% \mathrm{w} / \mathrm{w})$; cooling continued at 5 ${ }^{\circ} \mathrm{C} / \mathrm{min}$ to $20^{\circ} \mathrm{C}$. For AH-A, Fluconazole $(160 \mathrm{mg} / \mathrm{mL})$ was dissolved in anhydrous propan-2-ol at $70{ }^{\circ} \mathrm{C}$, the solution was cooled to $60{ }^{\circ} \mathrm{C}$ at $1{ }^{\circ} \mathrm{C} / \mathrm{min}$ and seeded with $\mathrm{AH}-\mathrm{A}(1 \% \mathrm{w} / \mathrm{w})$, cooling continued at $5{ }^{\circ} \mathrm{C} / \mathrm{min}$ to $20^{\circ} \mathrm{C}$. For AH-B, Fluconazole $(150$ $\mathrm{mg} / \mathrm{mL}$ ) was dissolved in anhydrous grade butan-2-one at $70{ }^{\circ} \mathrm{C}$. The solution was cooled to $60^{\circ} \mathrm{C}$ at $2{ }^{\circ} \mathrm{C} / \mathrm{min}$ and seeded with AH-B $(1 \% \mathrm{w} / \mathrm{w})$, cooling continued at $0.2{ }^{\circ} \mathrm{C} / \mathrm{min}$ to $20^{\circ} \mathrm{C}$, the product then held at $20{ }^{\circ} \mathrm{C}$ for 3 days. For AH-C, A hot (filtered) 
solution of fluconazole (anhydrous propan-2-ol, $60{ }^{\circ} \mathrm{C}, 85$ $\mathrm{mg} / \mathrm{mL}$ ) was crash cooled into a flask (on ice) containing AH-C seed $(5 \% \mathrm{w} / \mathrm{w})$. All anhydrous forms were isolated within a glove box held at $\leq 5 \%$ RH.

\subsection{Determination of Critical Water Activity}

The critical water activity for an anhydrate and hydrate system is the water activity value, at a defined temperature and pressure, at which the anhydrous and hydrate forms are in equilibrium. Conducting competitive studies, at defined water activities $\left(\mathrm{A}_{\mathrm{w}}\right)$ allows conversion to the more stable form via a solution mediated conversion pathway and therefore minimises the kinetic barriers associated with solid state conversion processes. ${ }^{12-13} \operatorname{ASPEN}^{35}$ (a process simulation software package) was used to calculate the water activity of water solvent mixtures through application of the non-random two-liquid model ${ }^{36}$ (NRTL). This model correlates the activity coefficients of a solvent with its mole fractions in the liquid phase. Solvent mixtures were prepared using propan-2-ol (anhydrous grade) and water. The water activity was confirmed using an Aqualab TDL (at $25^{\circ} \mathrm{C}$ ) which measures the relative humidity of a samples head space using a tuneable diode laser, calibrated against water activity standards. Solvent systems were initially saturated with the anhydrous form of interest, at or above the analysis temperature and excess anhydrous and $\mathrm{MH}$ forms were added to the resultant solution $(1 \mathrm{~mL})$ to achieve an approximate $1: 1 \mathrm{w} / \mathrm{w}$ mixture of anhydrous and $\mathrm{MH}$ forms. These slurries were held at $25{ }^{\circ} \mathrm{C}$ and the form present monitored using powder X-ray diffraction. The sample (slurry) was held on a lowbackground silicon wafer mount and covered with an X-ray transparent (polyimide) film; this added to prevent a change in the solvent composition and therefore form during the analysis. AH-A slurries were tested within 2 hours of mixture preparation with AH-B slurries being left for 1 week prior to analysis.

\subsection{Sample Preparation and Hydration}

Hydration was monitored using a gravimetric approach, involving manually weighing samples stored in a controlled humidity atmosphere. Samples were weighed over a period of six months, initially weekly decreasing in periodicity commensurate with the rate of hydration (see section 6.1 of the Supporting Information). This approach was used firstly because given the duration of the study it was impractical to use automated equipment and secondly because each anhydrous form was known to be non-hygroscopic (AH-A and AH-B adsorb $<0.005 \% \mathrm{w} / \mathrm{w}$ and $\mathrm{AH}-\mathrm{C}=0.06 \% \mathrm{w} / \mathrm{w}$ water at $80 \% \mathrm{RH}$, see section 5.5 of the Supporting Information) therefore any weight gain could be directly attributed to hydration. Full hydration requires the absorption of one mole of water, equating to $5.88 \% \mathrm{w} / \mathrm{w}$ relative to the anhydrous molecular weight. The conversion fraction $(\alpha)$ was calculated relative to this expected weight gain, therefore $\alpha=\%$ weight gain $/ 5.88$. No secondary quantification methodology was used during the sample weight monitoring period, as this could detrimentally affect the sample weight; however, the final form composition was confirmed on conclusion of the study, using powder X-ray diffraction.

Samples (35 mg each) were held at ambient temperature (19$23{ }^{\circ} \mathrm{C}$ ) and controlled humidity (in a sealed vessel). The humidity was maintained using saturated salt solutions of either $\mathrm{Mg}\left(\mathrm{NO}_{3}\right)_{2}$ $(54.5 \% \mathrm{RH})$ or $\mathrm{NaCl}(75.3 \% \mathrm{RH}) .{ }^{37}$ The sample weight was monitored using a Sartorius MC5 microbalance. The impact of particle size reduction and addition of $\mathrm{MH}$ seeds on the hydration process were also assessed. Particle size reduction was achieved using a pestle and mortar. To minimise the impact of grinding on the crystallinity, the grinding time and applied pressure were kept to a minimum. Multiple 10-second grinding periods were applied.
The particle size was monitored (microscopy) during grinding and once no further size change was observed ( $\sim 3$ repetitions) grinding was stopped. Approximately $0.5 \mathrm{~g}$ of each anhydrous polymorph, seeded with $5 \% \mathrm{w} / \mathrm{w}$ of ground $\mathrm{MH}$ was prepared. Monohydrate seeds were added to each anhydrous form in the following manner. The monohydrate was ground, as described above and $\sim 25 \mathrm{mg}$ accurately weighed into a $1 \mathrm{~cm}$ diameter, pressed aluminium foil weighing boat. (Grinding did not impact the MH hydration state, see section 5.3 of the Supporting Information.) The quantity of anhydrous polymorph required to deliver a $\mathrm{MH}$ seed level of $5 \% \mathrm{w} / \mathrm{w}$, relative to the pre-weighed $\mathrm{MH}$ seed, was calculated and then accurately weighed into a $15 \mathrm{~mL}$ glass vial. The ground $\mathrm{MH}$ was added to the surface of the anhydrous powder and the vial gently rolled to mix the contents. This was followed by multiple, short (5 x 3 second) periods of vortex mixing, tapping and rolling the vial between each. The MH seed weight was accounted for in the conversion fraction calculation. Replicates (5) of each sample type were weighed, this allowing for sample variability to be assessed.

\subsection{Microscopy}

The appearance of the $\mathrm{MH}$ crystals formed on hydration of $\mathrm{AH}-$ A, AH-B and AH-C were compared to those of the anhydrous forms. Powder was dispersed in a drop of silicone oil and viewed using a Nikon LV100 polarising light microscope, fitted with a range of objective lenses and a camera. Images were captured using Linkam Scientific LINK software ${ }^{38}$ v1.05.

\subsection{Calculation of Conformational Energies}

Adjustment and conformer energies ${ }^{39}$ for the various conformations of fluconazole, as found in the crystal structures of the $\mathrm{MH}, \mathrm{AH}-\mathrm{A}, \mathrm{AH}-\mathrm{B}$ and $\mathrm{AH}-\mathrm{C}$, were calculated. Density functional theory (DFT) calculations were carried out using the standalone functional B97-D (which includes Grimme's dispersion corrections ${ }^{40}$ ) together with the $6-31 \mathrm{G}+\mathrm{d}(\mathrm{d}, \mathrm{p})$ basis set using the quantum mechanics package Gaussian 09. This choice of functional was made on the basis that the model would accurately account for the intramolecular dispersion.

For the molecular energy calculations, initial molecular geometries were retrieved from the known crystal structures, as available in the CSD. Molecules were placed in isolation in the gas-phase and the geometries were relaxed, firstly keeping the torsion angles fixed $\left(\mathrm{E}_{\text {crys }}\right)$ and secondly without any torsional constraints $\left(\mathrm{E}_{\mathrm{gas}}\right)$. All geometry optimisations were carried out using tight convergence criteria. Each conformation was optimised in an independent simulation. These relaxations take the crystal conformation to the nearest equilibrium conformer (local or global). The adjustment energy $\left(E_{\text {adj }}\right)$ was calculated for each system by subtracting the electronic energy of the relaxed conformation in the gas-phase from the electronic energy of the constrained molecule in the gasphase. Thus, the adjustment energy for the molecule of fluconazole in the AH-A form would be calculated as $\mathrm{E}_{\text {adj }}[\mathrm{AH}-\mathrm{A}]=$ $\mathrm{E}_{\text {crys }}[\mathrm{AH}-\mathrm{A}]-\mathrm{E}_{\text {gas }}[\mathrm{AH}-\mathrm{A}]$. The adjustment energy represents the amount of conformational stability lost upon placing a particular fluconazole conformer from the gas-phase into the crystal structure. The relative conformer energy $\left(\Delta \mathrm{E}_{\mathrm{gas}}\right)$ was calculated as the difference between a given gas conformer and the most stable gas conformer of those calculated. Three different conformers were identified in the fluconazole form, $(\mathrm{C} 1, \mathrm{C} 2$ and $\mathrm{C} 3) \mathrm{C} 1$ being the most stable. Thus, for $\mathrm{AH}-\mathrm{A}, \Delta \mathrm{E}_{\mathrm{gas}}$ is calculated as the difference between $\mathrm{E}_{\text {gas }}[\mathrm{AH}-\mathrm{A}]$ and $\mathrm{E}_{\text {gas }}[\mathrm{C} 1]$. The total conformational energy penalty of the molecules in the different crystal structures is then calculated as the sum of the adjustment and the conformer energies, thus $\mathrm{E}_{\mathrm{conf}}=\mathrm{E}_{\mathrm{adj}}+\Delta \mathrm{E}_{\text {gas }}$. All energy values are reported in $\mathrm{kJ} / \mathrm{mol}$. 
After all geometry optimisations were completed the potential energy surface (PES) of fluconazole in the gas phase and water (using a continuum solvation model based on density, SMD, as implemented in Gaussian09) were calculated as a function of rotation of $\tau_{2-\mathrm{A}}, \tau_{2-\mathrm{B}}$ and $\tau_{\mathrm{OH}}$ from $0^{\circ}$ to $360^{\circ}$ in steps of $10^{\circ}$. The pertinent areas of those PESs were then put together and the conformational energy barriers, to convert from the conformers found in the different crystal structures (AH-A, AH-B, AH-C and $\mathrm{MH}$ ), were calculated.

\subsection{Calculation of Hydrogen Bond Interactions}

Crystal Explorer version $17.5^{41}$ was used for computing the hydrogen bond energies of fluconazole dimers and chains (as found in the IVUQOF and IVUQOF02 crystal structures respectively). The CE-B3LYP model for intermolecular energies was used as derived from $\mathrm{B} 3 \mathrm{LYP} / 6-31 \mathrm{G}(\mathrm{d}, \mathrm{p})$ electron densities. ${ }^{42-43}$

\subsection{Growth Morphology}

Crystal structures of the different forms were retrieved from the CSD and were geometry optimised within the Forcite tool available within BIOVIA Materials Studio. ${ }^{44}$ Calculations were carried out using the COMPASSII (v1.2) forcefield with forcefield assigned partial atomic charges. All atom-atom dispersionexchange-repulsion calculations were computed to a maximum interatomic distance cut-off of $15.5 \AA$. Electrostatic interactions were calculated using the Ewald summation method to an accuracy of $0.0001 \mathrm{kcal} / \mathrm{mol}$. Lattice geometry optimizations were carried out using the 'Smart' algorithm with convergence limits of $0.0001 \mathrm{kcal} / \mathrm{mol}$ for energy and $0.005 \mathrm{kcal} / \mathrm{mol} / \AA$ for force. Unit cell and atomic coordinates were all allowed to optimise freely. The optimised crystal structures were then used as input files for the calculation of crystal morphologies using the attachment energy method as implemented within the Growth Morphology tool, applying the same forcefield parameters used in the geometry optimisation.

\subsection{Scanning Electron Microscopy (SEM)}

A Carl Zeiss Supra 40VP field emission scanning electron microscope (FE-SEM) operated at high vacuum was used. Secondary electron images were recorded for each sample at an accelerating voltage of $3 \mathrm{kV}$ and a working distance of $12 \mathrm{~mm}$. Powder samples were adhered to an individual sticky-tab, mounted on a $12.5 \mathrm{~mm}$ diameter aluminium pin stub. Excess powder was removed by tapping and then dusting with particle free compressed air. Prior to analysis the prepared samples were sputter coated with approximately $10 \mathrm{~nm}$ of platinum using a Quorum Technologies Ltd., Q150TS coater operated at $20 \mathrm{~mA}$ for 1 minute. Images were collected using Zeiss Smart SEM software v5.06. ${ }^{45}$

\subsection{Differential Scanning Calorimetry (DSC)}

A TA Instruments Discovery DSC (heat-flux system), with an auto-sampler, was used. Samples of 1 to $3 \mathrm{mg}$ were heated in an aluminium T0 sample pan with a crimped lid. Samples were heated from 20 to $200{ }^{\circ} \mathrm{C}$ at a rate of $10{ }^{\circ} \mathrm{C} / \mathrm{min}$. Data was collected and analysis performed using TA Instruments TRIOS software. ${ }^{46}$

\subsection{Powder X-ray Diffraction (pXRD)}

The solid form of the monohydrate and each anhydrous polymorph used in the hydration studies was confirmed using a Bruker-AXS Ltd., D8 Advance, powder X-ray diffractometer, fitted with a theta-theta goniometer, automatic beam divergence slit and a LynxEye detector. Samples were prepared for analysis by filling a $0.7 \mathrm{~mm}$ diameter borosilicate capillary. The specimen was rotated whilst being irradiated with copper $\mathrm{K}$-alpha $\mathrm{A}_{1} \mathrm{X}$-rays (wavelength $=1.5406 \AA$ ) with the $\mathrm{X}$-ray tube operated at $40 \mathrm{kV} / 40 \mathrm{~mA}$. The analyses were performed with the goniometer running in continuous mode from $2-55^{\circ} 2 \theta$, step size $0.011^{\circ} 2 \theta$, step time 12 seconds. Data was collected using DIFRAC plus XRD Commander v2.6.1.

At the end of the hydration study the resultant solid form was confirmed using a Bruker AXS Ltd., D8 Endeavor, powder X-ray diffractometer, fitted with a theta-theta goniometer and a LynxEye $\mathrm{XE}-\mathrm{T}$ detector. The primary motorized slits were set at a constant illumination of $11 \mathrm{~mm}$ and anti-scattering slit set at a constant distance of $2.2 \mathrm{~mm}$. Samples were prepared for analysis on a low background cavity, silicon wafer mount. The wafer mount was rotated at $15 \mathrm{rpm}$, whilst being irradiated with copper K-alpha $\mathrm{X}_{1} \mathrm{X}$ rays with the $\mathrm{X}$-ray tube operated at $40 \mathrm{kV} / 40 \mathrm{~mA}$. The analyses were performed with the goniometer running in continuous mode from $2-55^{\circ} 2 \theta$, step size $0.019^{\circ} 2 \theta$, step time 0.10 seconds. Data was collected using DIFRAC Measurement Centre v7.3.1. Analysis was performed using Bruker AXS DIFFRAC.EVA v4.2.1.10. ${ }^{47}$

\section{RESULTS}

3.1. Physicochemical Characterisation of Anhydrous Polymorphs

Characterisation was carried out using DSC, pXRD and SEM on both initial and ground samples to establish the impact of particle size reduction on the particle properties. From a comparison of the measured and simulated (from the crystal structure) pXRD patterns, each solid form was confirmed to be a single phase; however, AH-C was found to contain just detectable levels (typically detection limit 1\%) of AH-A (see section 5 of the Supporting Information).

It is commonly accepted that milling crystalline materials can induce surface disorder, this in turn affecting the physicochemical properties exhibited. ${ }^{48-49}$ Surface disorder can act as nucleation points for form conversion. When comparing data for initial and ground samples there was no detectable loss of crystallinity; for pXRD, both peak widths and positions remained the same and for DSC melt onset and enthalpy values were within the variability expected from this analysis technique (Table 2 and section 5 of the Supporting Information).

Table 2 Differential Scanning Calorimetry Data: onset melting temperature $\left(T_{\text {fus }}\right)$ and enthalpy of fusion $\left(\Delta \mathbf{H}_{\text {fus }}\right)$. Relative enthalpy of fusion, with respect to the most stable form, are also given $\left(\Delta \mathbf{H}_{\text {form }}\right)$.

\begin{tabular}{llll}
\hline & $\mathbf{T}_{\text {fus }}\left({ }^{\circ} \mathbf{C}\right)$ & $\Delta \mathbf{H}_{\text {fus }}(\mathbf{k J} / \mathbf{m o l})$ & $\Delta \mathbf{H}_{\text {form }}(\mathbf{k J} / \mathbf{m o l})$ \\
\hline AH-A & 138.7 & 35.9 & \multirow{2}{*}{2.4} \\
AH-A-ground & 138.6 & 35.9 & \\
\hline AH-B & 137.5 & $38.3^{*}$ & \multirow{2}{*}{0.0} \\
AH-B-ground & 137.5 & 38.3 & \\
\hline AH-C & 138.9 & 34.7 & \multirow{2}{*}{3.7} \\
AH-C-ground & 139.1 & 34.5 & \\
\hline
\end{tabular}

*In order to estimate the variability, five replicate measurements were performed on AH-B. The needle-like crystal morphology found for AH-B making it the most challenging material to prepare for analysis. The mean of these replicates was $38.3 \mathrm{~kJ} / \mathrm{mol}$ with a standard deviation of $0.2 \mathrm{~kJ} / \mathrm{mol}$. (see section 5 of the Supporting Information)

Scanning electron microscopy (Figure 2) shows images for the three anhydrous polymorphs studied both before and after grinding. AH-A consists of angular prisms, typically less than $40 \mu \mathrm{m}$ in size, with some particle aggregation. AH-B consists of needles of $2-3 \mu \mathrm{m}$ in width and up to $120 \mu \mathrm{m}$ in length. AH-C consists of flakes $(5-20 \mu \mathrm{m})$ aggregated into larger sintered particles averaging $60 \mu \mathrm{m}$ in size. In each case, grinding effectively reduced the particle size. For AH-A the particle shape has been impacted with 
many particles appearing more rounded. For AH-B grinding appears to have shortened the needles, but not impacted the needle width. For AH-C the aggregates have been broken to some extent, with the flake like morphology retained. Sizes are estimated from analysis of particles within a larger collection of images, with only representative images presented here.
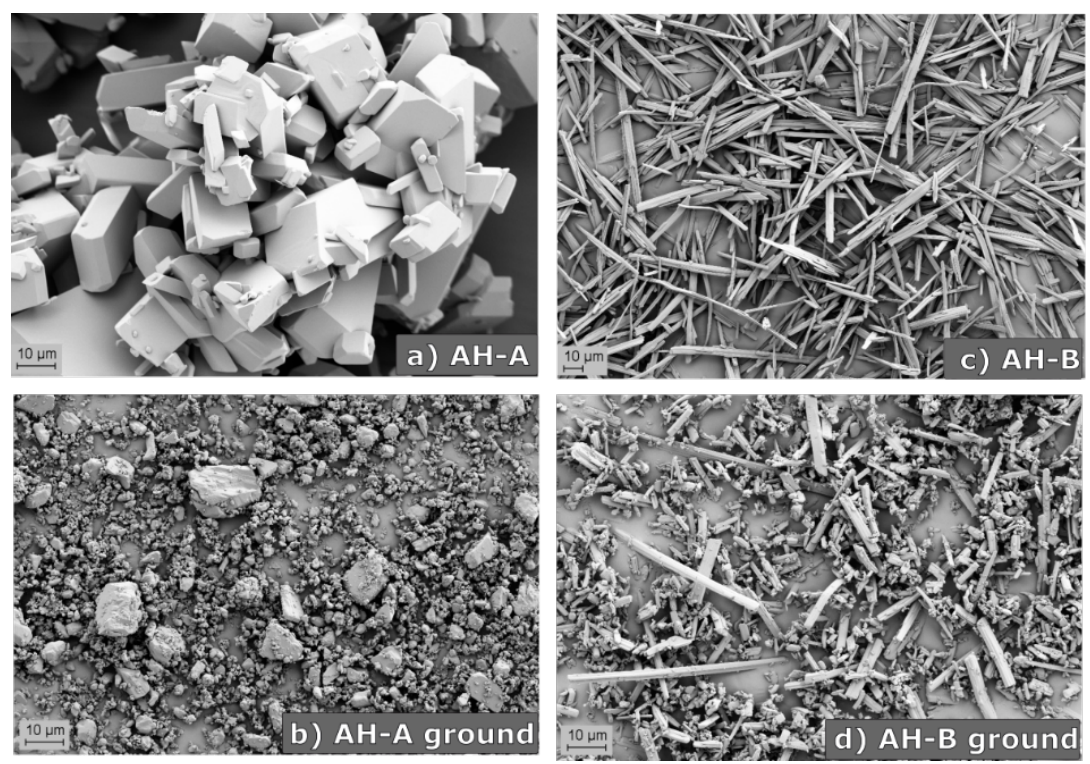

Figure 2 Scanning Electron Micrographs of fluconazole AH-A (a,b), AH-B (c,d) and AH-C (e,f), before (a,c,e) and after grinding (b,d,f).

\subsection{Critical water activity for anhydrate to $\mathrm{MH}$ conversion}

The critical water activity for $\mathrm{MH}$ versus $\mathrm{AH}-\mathrm{A}$ and $\mathrm{AH}-\mathrm{B}$ was established at $25{ }^{\circ} \mathrm{C}$. Table 3 summarises the results of slurry experiments starting with 1:1 mixtures of the anhydrous form of interest and the $\mathrm{MH}$. At a water activity $\left(\mathrm{A}_{\mathrm{w}}\right)$ of $\leq 0.2$, the $\mathrm{MH}$ converts to the respective anhydrous form. Only at a $A_{w}$ above 0.30 do we see full conversions to the $\mathrm{MH}$ for both anhydrous forms. Thus, we infer that the critical water activity for AH-A versus $\mathrm{MH}$ is in the range between 0.20 and 0.30 , and for $\mathrm{AH}-\mathrm{B}$ between 0.30 and 0.39 . At low water activity $\mathrm{AH}-\mathrm{C}$ was found to convert to AH-A within 30 min of slurry preparation and therefore it was not possible to establish the critical water activity between $\mathrm{AH}-\mathrm{C}$ and the $\mathrm{MH}$. The differing critical water activity values found for $\mathrm{MH}$ relative to $\mathrm{AH}-\mathrm{A}$ and $\mathrm{AH}-\mathrm{B}$ are in line with the relative stability of these polymorphs. Note that during AH-B seed preparation, a $\mathrm{MH}$ and $\mathrm{AH}-\mathrm{A}(1: 1 \mathrm{w} / \mathrm{w})$ slurry, in anhydrous butan-2-one, was found to convert to $\mathrm{AH}-\mathrm{B}$, indicating $\mathrm{AH}-\mathrm{B}$ as the more thermodynamically stable polymorph at room temperature.

Table 3 Solid forms identified after equilibration of anhydrous: $\mathrm{MH}$ mixtures in propan-2-ol/water at $25^{\circ} \mathrm{C}$.

\begin{tabular}{lll}
\hline $\begin{array}{l}\text { Water } \\
\text { activity }\left(\mathbf{A}_{\mathbf{w}}\right)\end{array}$ & $\begin{array}{l}\text { 1:1 AH-A:MH } \\
\text { starting mixture }\end{array}$ & $\begin{array}{l}\text { 1:1 AH-B:MH } \\
\text { starting mixture }\end{array}$ \\
\hline 0.00 & AH-A & AH-B \\
0.10 & AH-A & AH-B \\
0.20 & AH-A & AH-B \\
0.30 & MH & AH-B \\
0.39 & MH & MH \\
0.49 & MH & MH \\
\hline
\end{tabular}

\subsection{Hydration of polymorphic forms}

Figure 3 shows the hydration kinetics of the three anhydrous fluconazole polymorphs in the form of conversion-time plots.
Data at two relative humidities are provided, 54.5 and $75.3 \%$. Given that both these values are in excess of the measured critical water activity it would be expected that in all experiments the anhydrous forms would be metastable with respect to the $\mathrm{MH}$.

Figure 3 then illustrates a number of key features. It is apparent that hydration rates are dependent not only on the relative humidity but also on the starting polymorphic form. For the ascrystallised, unground samples all three anhydrous forms demonstrated a kinetic barrier to hydration at $54.4 \% \mathrm{RH}$ (Figure 3a) with no weight gain observed over 6 months. Increasing the RH to 75.3 $\%$ (Figure $3 \mathrm{~b}$ ) accelerates the hydration kinetics which are now clearly different for each anhydrous form. For the first 16 weeks, hydration was only observed for $\mathrm{AH}-\mathrm{A}$ and $\mathrm{AH}-\mathrm{C}$ with the hydration rate for $\mathrm{AH}-\mathrm{C}$ being markedly faster $(0.0473 \alpha /$ day $)$ than that of AH-A (0.0109 $\alpha /$ day) (Table 4). After a 16-week induction period there is a small yet measurable gain in weight $(0.0002$ $\alpha /$ day) for AH-B with the rate increasing over time $(0.0008 \alpha$ /day at 25 weeks). AH-B thus experiences a higher kinetic barrier to hydration at $75.3 \% \mathrm{RH}$ than $\mathrm{AH}-\mathrm{A}$ or $\mathrm{AH}-\mathrm{C}$.

Table 4 Maximum observed slope of conversion fraction with time (as d $\alpha$ / day) at 54.5 and $75.3 \%$ RH.

\begin{tabular}{lllll}
\hline \%RH & & AH-A & AH-B & AH-C \\
\hline \multirow{3}{*}{54.5} & As-cryst. & 0.0000 & 0.0000 & 0.0000 \\
& Seeded & 0.0002 & 0.0000 & 0.0019 \\
& Ground & 0.0011 & 0.0000 & 0.0013 \\
\hline \multirow{3}{*}{75.3} & As-cryst. & 0.0109 & 0.0008 & 0.0473 \\
& Seeded & 0.1023 & $0.0141^{*}$ & 0.1188 \\
& Ground & 0.1329 & 0.0048 & 0.1152 \\
\hline
\end{tabular}

*Hydration slowed after 60 days to $0.0020 \mathrm{~d} \alpha /$ day. The maximum observed hydration rate is estimated from the slope of the weight gain across consecutive data points. 

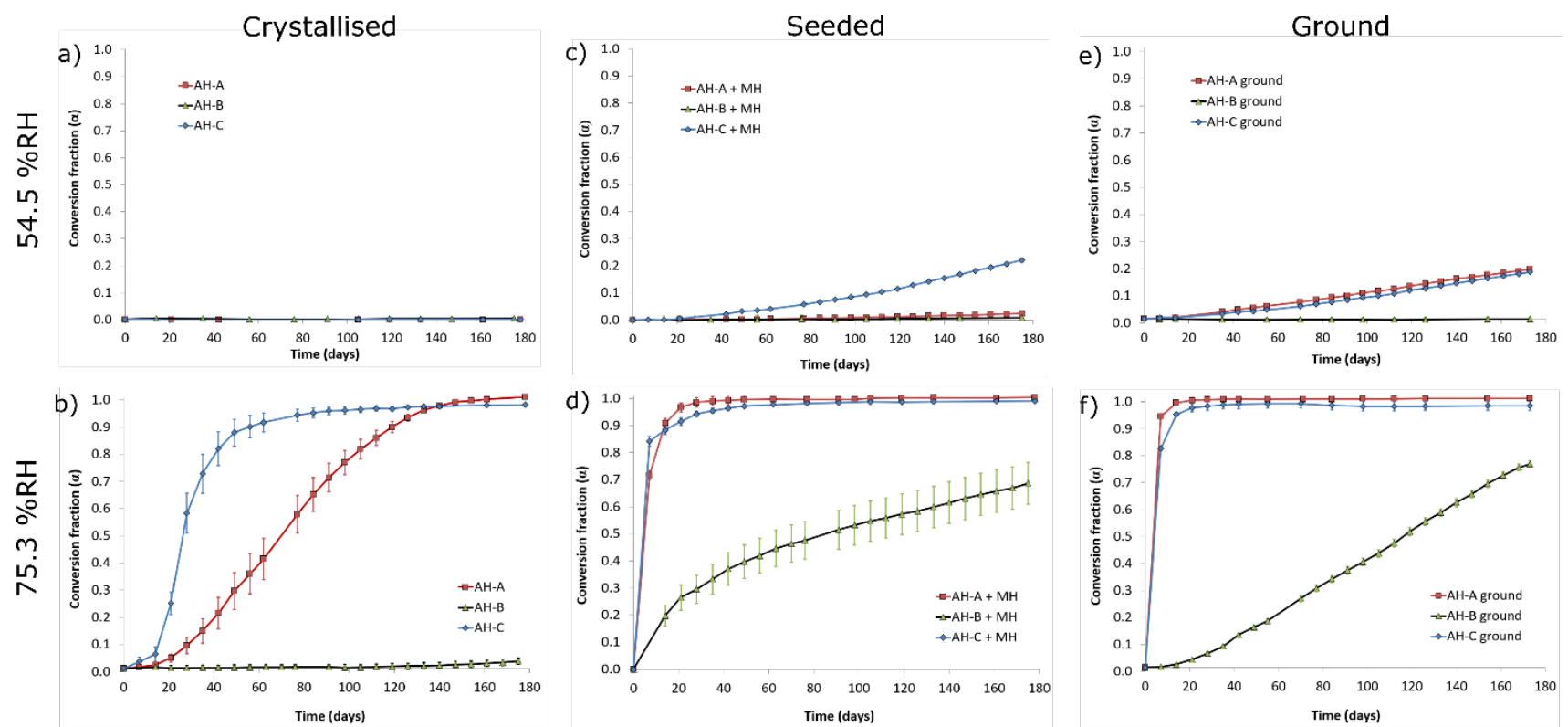

Figure 3 Water vapour sorption of anhydrous fluconazole polymorphs held at 54.5 (a,c,e) and $75.3 \%$ RH (b,d,f): (a, b) as-crystallised, (c, d) including the impact of $\mathrm{MH}$ seed addition $(5 \% \mathrm{w} / \mathrm{w})$ and $(\mathrm{e}, \mathrm{f})$ particle size reduction (ground). Values calculated from an average weight gain of 5 sample replicates held in a sealed humidity vessel. Error bars are given for all data sets but may not be discernible where the variability was low.

The impact of $\mathrm{MH}$ seeding on the kinetic barrier at $54.5 \% \mathrm{RH}$ is seen in Figure 3c. This appears to have most effect on AH-A and $\mathrm{AH}-\mathrm{C}$ which now become susceptible to hydration while $\mathrm{AH}-$ $\mathrm{B}$ remains kinetically stable. Clearly the hydration rate of $\mathrm{AH}-\mathrm{A}$ is significantly slower than that of AH-C. At $75.3 \% \mathrm{RH}$ (Figure 3d) seed addition had a dramatic effect with AH-A and AH-C now demonstrating similar hydration behaviour. For AH-B the 16week induction period, seen without seeding, is no longer present, although the hydration rate remains relatively slow compared to AH-A and AH-C (e.g., $0.0141 \alpha /$ day (initial rate) relative to $0.1188 \alpha /$ day for AH-C, Table 4). The impact of particle size reduction, as revealed through the ground samples is seen in Figure $3 \mathrm{e}$ and $\mathrm{f}$. For $\mathrm{AH}-\mathrm{A}$ and $\mathrm{AH}-\mathrm{C}$ the results mirror that of seeding with both forms exhibiting similar hydration behaviour. AH-B, however, continues to show much slower kinetics. An absence or decrease in hydration induction time suggesting that grinding may have removed the barrier to $\mathrm{MH}$ nucleation on the surface of the $\mathrm{AH}-\mathrm{C}$ crystals. For AH-A hydration occurred at a faster rate than seen with seed addition, suggesting that there is an additional factor at play. AH-B continues to present a kinetic barrier to hydration at $54.5 \% \mathrm{RH}$, however at $75.3 \% \mathrm{RH}$ hydration was observed with an induction period of approximately 20 days, after which hydration continued at a steady rate.

Very little variability was found within the weight gain of sample replicates with the exception of $\mathrm{AH}-\mathrm{A}, \mathrm{AH}-\mathrm{C}$ (without grinding or seed addition) and AH-B (seeded) held at $75.3 \% \mathrm{RH}$, where variability was seen in sample replicate weight gain. For AH-A and $\mathrm{AH}-\mathrm{C}$ the variability occurred during hydration but did not impact the induction period (prior to hydration) or the time taken for hydration to complete; the variability being at a maximum at a conversion fraction of 0.5 . This may simply be related to a physical difference between sample replicates, such as particle size. However, for AH-B (seeded) variability increased during the first 60 days exposure at $75.3 \% \mathrm{RH}$, within this period each sample hydrated to a differing conversion fraction, after this initial period each sample then continued to hydrate at the same rate, albeit offset (see section 6 of the Supporting Information). Variability was not seen for ground $\mathrm{AH}-\mathrm{B}$, where $\mathrm{MH}$ nucleation was first required on the surface of the AH-B crystals, this suggest that the variability seen in the seed data set was due to either the seed distribution or seed contact with the AH-B crystals; once $\mathrm{MH}$ nucleation was established within the AH-B crystals, variability in the hydration rate was no longer apparent.

The solid form identified at the end of the study, summarised in Table 5, is consistent with the observed weight gain. Thus, samples with a larger weight gain were found to be either fully or predominantly the $\mathrm{MH}$ form while those with a smaller weight gain were found to be predominantly the starting anhydrous form. Interestingly, for $\mathrm{AH}-\mathrm{C}$, the ground sample held at $54.5 \% \mathrm{RH}$ has a higher level of AH-A present at the end of the six months study than found for the initial sample, suggesting that conversion of $\mathrm{AH}-\mathrm{C}$ to $\mathrm{AH}-\mathrm{A}$ has occurred over time.

Table 5 Solid form identified after six months exposure of samples to either 54.5 or $\mathbf{7 5 . 3} \% \mathrm{RH}$. (from powder X-ray diffraction analysis, see section 7 of the Supporting Information).

\begin{tabular}{llccc}
\hline \multirow{2}{*}{$\%$ RH } & & \multicolumn{3}{c}{ Starting Anhydrous Form } \\
\cline { 3 - 5 } & & AH-A & AH-B & AH-C \\
\hline \multirow{2}{*}{54.5} & As-cryst. & A & B & C \\
& Seeded & A, (MH) & B, (MH) & C, (MH), (A)* \\
& Ground & A, (MH) & B & C, (MH), (A)* \\
\hline \multirow{2}{*}{75.3} & As-cryst. & MH, (A)* & B, (MH)* & MH \\
& Seeded & MH & MH, (B) & MH \\
& Ground & MH & MH, (B) & MH \\
\hline
\end{tabular}

Minor forms are given in parenthesis, *indicating the presence of only a trace of this form. $\mathrm{A}=\mathrm{AH}-\mathrm{A}, \mathrm{B}=\mathrm{AH}-\mathrm{B}$ and $\mathrm{C}=\mathrm{AH}-\mathrm{C}$.

We confirmed experimentally that all fluconazole forms convert directly to the monohydrate without any intermediates. For $\mathrm{AH}-\mathrm{A}$ and $\mathrm{AH}-\mathrm{C}$, environmental powder X-ray diffraction at 90 $\% \mathrm{RH}\left(25^{\circ} \mathrm{C}\right)$ confirmed that the hydration of $\mathrm{AH}-\mathrm{A}$ and $\mathrm{AH}-\mathrm{C}$ proceeds directly to the monohydrate with no intermediate form (see section 8 of the Supplementary Information). For AH-B, pXRD patterns for partially converted AH-B confirm that the 
hydration of AH-B also proceeds directly to the monohydrate with no intermediate form (see section 7 of the Supplementary Information).

\subsection{Structural changes required during the hydration pro-} cess

In this section the structural changes required for the hydration of the different anhydrous forms can be classified in two types: a) conformational variations and b) crystal structure variations, both are influential on hydration to a differing extent relative to the anhydrous form studied. Here we compare the conformations and the crystal packing of the three anhydrous forms with that of the $\mathrm{MH}$.

\section{Conformational variations}

In order to illustrate the rotations required for conversion of each of the conformations found in the anhydrous polymorphs to that found in the $\mathrm{MH}$, we have oriented all of the crystal conformations along the $\mathrm{O} 13-\mathrm{C} 12$ bond in Figure 4 and summarised the torsion angle values and rotational changes required in Table 6. The six main torsion angles depicted in Figure 1 are analysed: i) $\tau_{\mathrm{Ph}}$ which defines the orientation of the diflurophenyl group, ii) $\tau_{\mathrm{OH}}$ which defines the orientation of the hydroxyl group, iii) $\tau_{\mathrm{t} 1-\mathrm{A}}$ and $\tau_{\mathrm{t} 1-\mathrm{B}}$ which define the orientation of the first $-\mathrm{CH}_{2}$-triazole group and iv) $\tau_{\mathrm{t} 2-\mathrm{A}}$ and $\tau_{\mathrm{t} 2-\mathrm{B}}$ which define the relative orientation of the second $-\mathrm{CH}_{2}$-triazole group. The crystal structures of the $\mathrm{MH}$, $\mathrm{AH}-\mathrm{A}$ and $\mathrm{AH}-\mathrm{C}$ are centrosymmetric and thus have inversion symmetry. This means, that these forms contain the conformation reported in the asymmetric unit and its inverted version. For the sake of simplicity, we have only analysed one set of conformations, however the inverted versions (all torsions with opposite sign) will also be present. All crystal structures contain one molecule in the asymmetric unit $\left(Z^{\prime}=1\right)$ except for AH-B which contains two $\left(Z^{\prime}=2\right)$. Thus, two conformations (M1 and M2) are analysed for AH-B whilst only one is analysed for the rest of the forms.
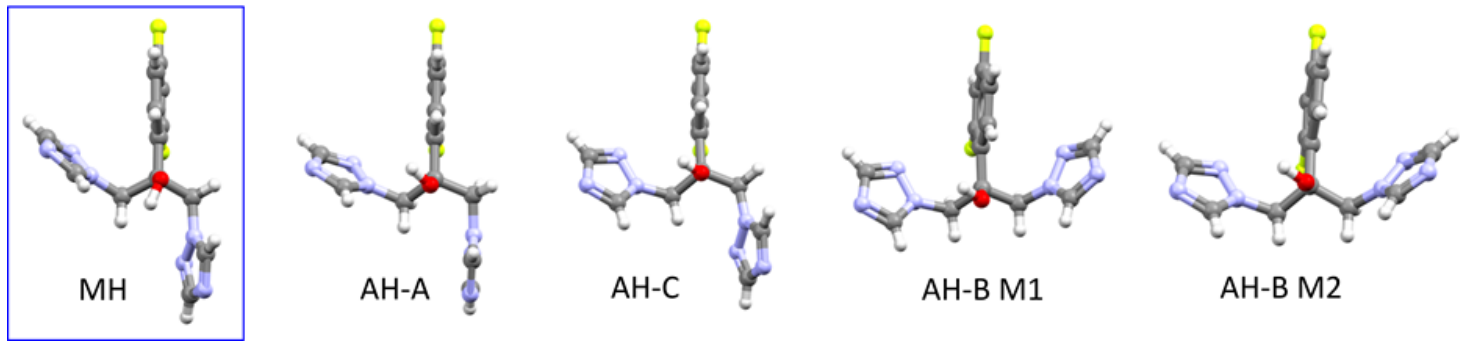

Figure 4 Crystal conformations in MH, AH-A, AH-C, AH-B M1 and AH-B M2.

Table 6 Torsion values in crystal conformations of fluconazole in the MH, and AH-A, AH-B and AH-C crystal structures and the required torsional variations for the anhydrous crystal conformations to be converted to the MH crystal conformation.

\begin{tabular}{|c|c|c|c|c|c|c|}
\hline \multirow[b]{3}{*}{ Torsion definition } & \multicolumn{6}{|c|}{ Torsion $\left({ }^{\circ}\right)$} \\
\hline & $\tau \mathbf{P h}$ & $\tau \mathrm{OH}$ & $\tau \mathrm{t} 1-\mathrm{A}$ & $\tau t 1-B$ & $\tau \mathrm{t} 2-\mathrm{A}$ & $\tau \mathrm{t} 2-B$ \\
\hline & 2-1-12-13 & 1-12-13-34 & 13-12-14-17 & 12-14-17-18 & 13-12-24-27 & 12-24-27-28 \\
\hline MHcrys & 173.7 & 157.8 & 63.4 & 101.1 & 65.5 & 102.1 \\
\hline AH-Acrys & 185.1 & 43.4 & 74.6 & 101.2 & 73.0 & 99.7 \\
\hline AH-B M1crys & 190.8 & 55.3 & 59.9 & 79.3 & -55.5 & -91.8 \\
\hline AH-B M2crys & 187.7 & 48.4 & 60.5 & 76.9 & -64.9 & -83.9 \\
\hline \multirow[t]{3}{*}{ AH-Ccrys } & 178.7 & 54.3 & 58.2 & 73.1 & 55.8 & 89.6 \\
\hline & \multicolumn{6}{|c|}{ Torsional Variation $\left({ }^{\circ}\right)$} \\
\hline & $\Delta \tau \mathrm{Ph}$ & $\Delta \tau \mathbf{O H}$ & $\Delta \tau \mathrm{t} 1-\mathrm{A}$ & $\Delta \tau \mathrm{t} 1-\mathrm{B}$ & $\Delta \tau \mathbf{t} 2-\mathrm{A}$ & $\Delta \tau \mathrm{t} 2-\mathrm{B}$ \\
\hline AH-Acrys to MHcrys & -11.4 & 114.4 & -11.2 & -0.1 & -7.5 & 2.4 \\
\hline AH-B M1crys to MHcrys & -17.1 & 102.5 & 3.5 & 21.8 & 121.0 & -166.1 \\
\hline AH-B M2crys to MHcrys & -14.0 & 109.4 & 2.9 & 24.2 & 130.4 & -174.3 \\
\hline AH-Ccrys to MHcrys & -5.0 & 103.5 & 5.2 & 28.0 & 9.7 & 12.5 \\
\hline
\end{tabular}

Analysis of the conformational data in Figure 4 and Table 6 revealed that the crystal conformations found in $\mathrm{AH}-\mathrm{A}$ and $\mathrm{AH}-\mathrm{C}$ are very similar to the $\mathrm{MH}$ crystal conformation. Only the acyclic hydroxyl group requires a conformational change, whilst the remaining torsions require only minor adjustments $\left(\Delta \tau<30^{\circ}\right)$. Rotation of the hydroxyl group should be facile since it would not be significantly hindered sterically, only a proton will change its orientation significantly. By contrast, both crystal conformations (M1 and M2) in AH-B require a conformational change in the $\mathrm{OH}$ group and significant changes in two torsions defining the relative orientation of the second $-\mathrm{CH}_{2}$-triazole group. The conformational changes required to go from the AH-B crystal conformation to the $\mathrm{MH}$ crystal conformation are major and result in major shape changes in the fluconazole conformation (Figure 4).

To explore this further the conformer and adjustment energies for all crystal conformations in the gas-phase were calculated. (see section 9 of the Supplementary Information.) Upon geometry optimisation of all different crystal conformations, we identified three distinct conformers $\mathrm{C} 1, \mathrm{C} 2$ and $\mathrm{C} 3$ (Table 7). 
Table 7 Conformer energies in the gas-phase and water and their correspondence with the various forms of fluconazole. Energies computed at the B97-d/6-31+G** level of theory.

\begin{tabular}{|c|c|c|c|c|c|c|}
\hline $\begin{array}{l}\text { Form } \\
\text { Conformation }\end{array}$ & $\begin{array}{c}\text { Gas } \\
\text { Conformer }\end{array}$ & $\begin{array}{c}\Delta \mathbf{E}_{\text {gas }} \\
(\mathrm{kJ} / \mathrm{mol})\end{array}$ & $\begin{array}{c}\Delta \mathbf{E}_{\text {water }} \\
(\mathrm{kJ} / \mathrm{mol})\end{array}$ & $\begin{array}{c}\Delta \tau_{\mathrm{OH}} \\
\left({ }^{\circ}\right)\end{array}$ & $\begin{array}{c}\Delta \tau_{\mathrm{t} 2-\mathrm{A}} \\
\left.\quad{ }^{\circ}\right)\end{array}$ & $\begin{array}{c}\Delta \tau_{\mathrm{t} 2-\mathrm{B}} \\
\left({ }^{\circ}\right)\end{array}$ \\
\hline $\begin{array}{l}\text { AH-A } \\
\text { AH-C }\end{array}$ & $\mathrm{C} 1$ & 0.0 & 4.8 & 67.5 & 62.8 & 93.7 \\
\hline $\begin{array}{l}\text { AH-B M1 } \\
\text { AH-B M2 }\end{array}$ & $\mathrm{C} 2$ & 3.3 & 1.8 & 57.6 & -70.7 & -99.5 \\
\hline $\mathrm{MH}$ & C3 & 4.7 & 0.0 & 183.0 & 62.6 & 95.8 \\
\hline
\end{tabular}

The three conformers have similar stabilities, all being within 5 $\mathrm{kJ} / \mathrm{mol}$ of the most stable conformer. Interestingly, the order of stabilities changes with the solvation environment. For example, the $\mathrm{MH}$ conformer, $\mathrm{C} 3$, is the most stable in water but the least stable in the gas-phase. By contrast, AH-A conformer, $\mathrm{C} 1$, is the most stable in the gas-phase but the least stable in water whilst $\mathrm{C} 2$ has intermediate stability in both environments. C1 and C3 only differ in the orientation of the hydroxyl group whilst $\mathrm{C} 2$ differs from $\mathrm{C} 3$ in the orientation of the hydroxyl group and the orientation of the second $-\mathrm{CH}_{2}$-triazole group. $\mathrm{C} 2$ differs from $\mathrm{C} 1$ in the orientation of the second $-\mathrm{CH}_{2}$-triazole group. All these conformers require some level of conformational adjustments in the crystal structures of the different forms, those vary from just $4 \mathrm{~kJ} / \mathrm{mol}$ to almost $10 \mathrm{~kJ} / \mathrm{mol}$, which is typical in molecular crystals. ${ }^{39}$

Finally, we calculated the energy barriers for converting the conformer in AH-B (C2) into conformer AH-A/C (C1) via rotation of $\tau_{\mathrm{t} 2-\mathrm{B}}$ first and $\tau_{\mathrm{t} 2-\mathrm{A}}$ second and for converting conformer $\mathrm{AH}-\mathrm{A} / \mathrm{C}(\mathrm{C} 1)$ into conformer $\mathrm{MH}(\mathrm{C} 3)$ via rotation of $\tau_{\mathrm{OH}}$. The conformational energy pathway (Figure 5) reveals that the conformation found in AH-B needs to cross three energy barriers of 29,14 and $11 \mathrm{~kJ} / \mathrm{mol}(21,24$ and $18 \mathrm{~kJ} / \mathrm{mol}$ in water) and rotate three bonds by a cumulative total of $450^{\circ}$ to convert to the monohydrate conformer.

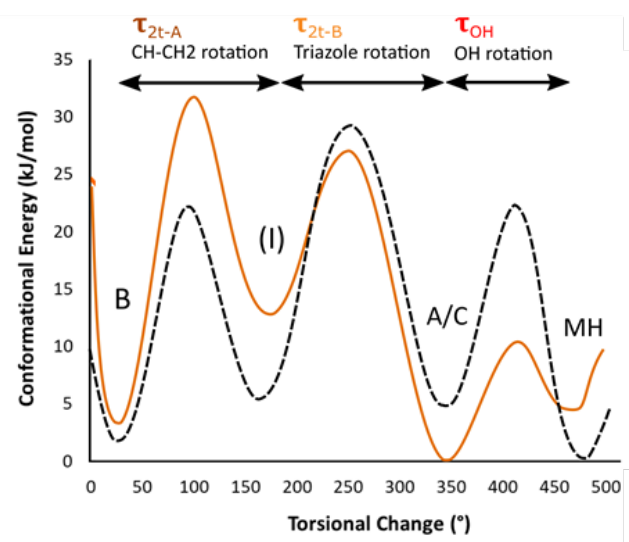

Figure 5 Conformational energy pathway for conformer interconversions. Calculations were performed at the B97-d/6-31+G** level of theory in the gas-phase (orange line) and using an SMD solvation model for water (black dashed line). In contrast, the conformers in $\mathrm{AH}-\mathrm{A} / \mathrm{C}$ only require the crossing of one energy barrier of $11 \mathrm{~kJ} / \mathrm{mol}(18 \mathrm{~kJ} / \mathrm{mol}$ in water $)$ and rotate $\sim 100^{\circ}$ in the acyclic hydroxyl group. Thus, the conformational change required for the hydration process is significantly more dramatic for $\mathrm{AH}-\mathrm{B}$ than $\mathrm{AH}-\mathrm{A} / \mathrm{C}$.

\section{Crystal Structure Variations}

Looking at the hydrogen bonding interactions found in the various structures. AH-A forms discrete dimers and $\mathrm{AH}-\mathrm{B}$ and $\mathrm{AH}-\mathrm{C}$ chain motifs between fluconazole molecules (Figure $6 \mathrm{~b}-\mathrm{d}$ ). Those hydrogen bond interactions were calculated to be stronger for the hydrogen bond chains $(60 \mathrm{~kJ} / \mathrm{mol}$ per $\mathrm{HB})$ than for the hydrogen bond dimers $(50 \mathrm{~kJ} / \mathrm{mol}$ per $\mathrm{HB})$. All fluconazole-fluconazole hydrogen bonds are disrupted by water in the monohydrate (Figure 6a). In the $\mathrm{MH}$ form, water interacts with fluconazole via three hydrogen bonds, a water environment commonly seen in organic hydrates. $^{50}$

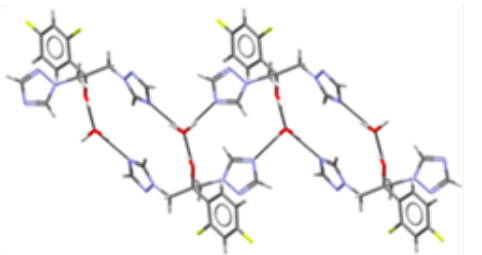

(a) $\mathrm{MH}$
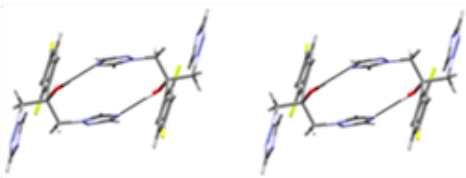

(b) $\mathrm{AH}-\mathrm{A}$

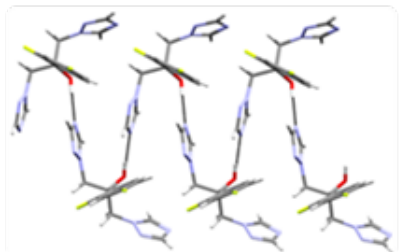

(c) $\mathrm{AH}-\mathrm{B}$

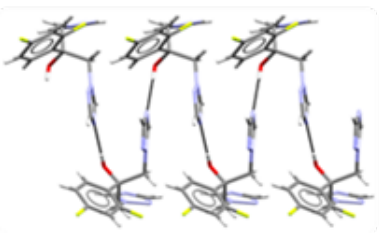

(d) $\mathrm{AH}-\mathrm{C}$

Figure 6 Hydrogen bonding network found in fluconazole (a) $\mathrm{MH}$, (b) AH-A, (c) AH-B and (d) AH-C.

Deriving crystal structure similarities for these forms was challenging; because the hydration occurs with changes in composition, expansion of cells and conformational changes, classic tools for structure similarity analysis (i.e. COMPACK algorithm) ${ }^{51}$ do fail to reveal detailed similarities and thus an expert analysis was done visually by overlaying molecular fragments with Materials Mercury. ${ }^{52}$

The similarity between the anhydrous and monohydrate structures can be considered by comparing the position and orientation of the molecules within the structures. A molecule would be described to have positional and orientational similarity if the molecules in the anhydrous and MH structures were found to be at the same site and the functional groups were aligned. When assessing 
positional similarity, the impact of the water molecules on the spacing of the fluconazole molecules was considered. The hydrogen bonded dimers found in the AH-A structure form a 2D layer parallel to the $\{111\}$ planes. The molecules within this plane have both positional and orientational similarity with the MH (110) plane. The presence of water molecules in the $\mathrm{MH}$ structure increases the molecular distances between the fluconazole molecules within the dimer (Figure $7 \mathrm{a}$ and $\mathrm{b}$ ). Looking three dimensionally, the molecules within the adjacent plane retain orientational similarity however they are positionally offset, therefore a translation of the plane would be required to match the MH structure. A high level of similarity can also be found by comparing the $\mathrm{MH}$ and $\mathrm{AH}-\mathrm{C}$ structures. Here a common 2D layer consisting of parallel chains is found in the (200) plane of AH-C compared

(a) $\mathrm{AH}-\mathrm{A}$

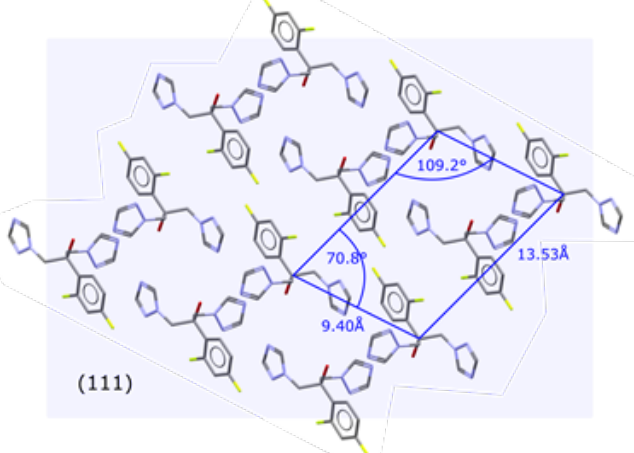

(c) $\mathrm{AH}-\mathrm{B}$

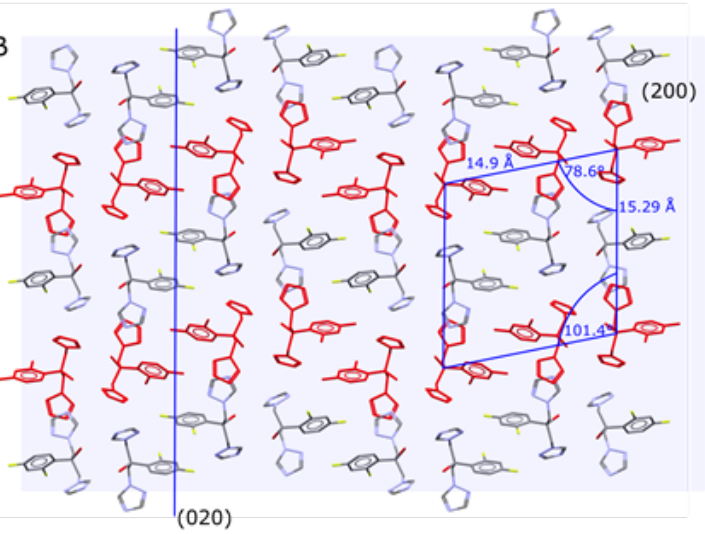

(e) $\mathrm{AH}-\mathrm{C}$

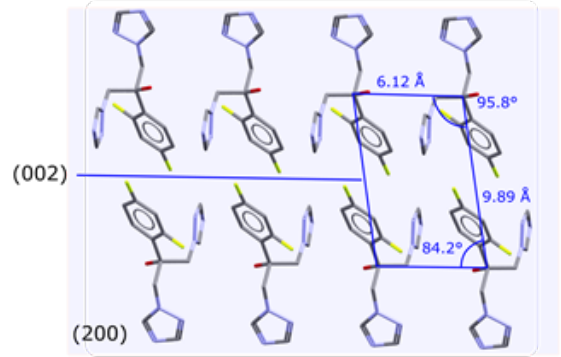

to the (0-11) plane of the MH. Since the water in the MH structure sits offset from this plane, there is very little positional difference between the fluconazole molecules in the AH-C and $\mathrm{MH}$ structures (Figure 7e and $\mathrm{f}$ ). There is also a degree of 3D similarity through the $\{002\}$ planes, all molecules are found to have positional similarity and half of the molecules have orientational similarity.

Finally considering AH-B (Figure 7c) there is a degree of positional similarity with the $\mathrm{MH}$ structure (Figure $7 \mathrm{~d}$ ) found comparing the (200) plane of AH-B to the (100) plane for the MH. The similarity is restricted within four localised fluconazole molecules and does not extend to adjacent molecules in the (200) plane, these four molecules are found to repeat within this plane, each repeat being offset by approximately one fluconazole molecule.

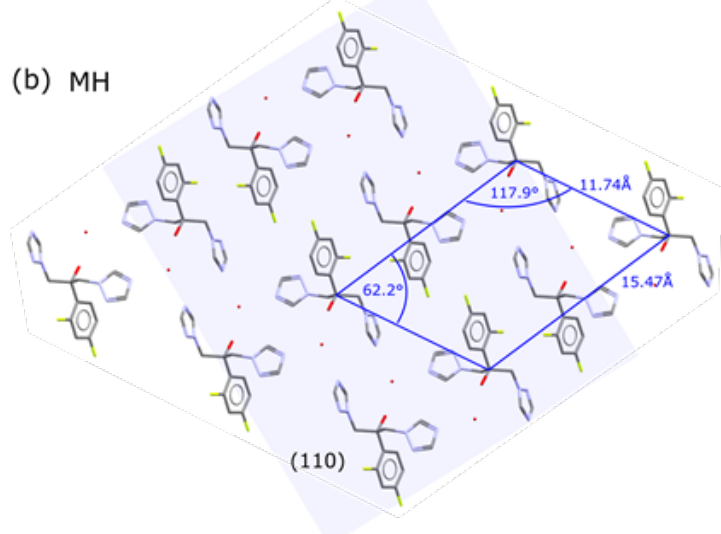

(d) $\mathrm{MH}$

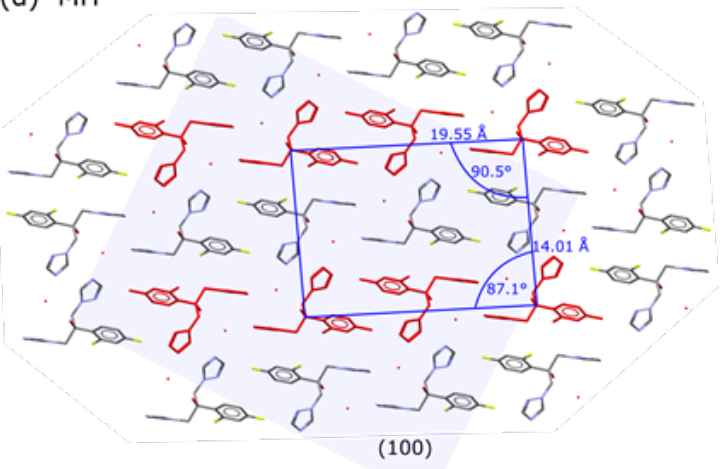

(f) $\mathrm{MH}$

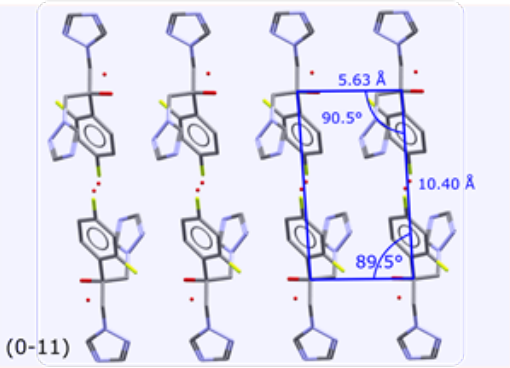

Figure 7 Similarity found between anhydrous and MH structures. (a) AH-A (111) and MH (110) (b) AH-B (200) and MH (100) and (c) $\mathrm{AH}-\mathrm{C}(200)$ and $\mathrm{MH}(0-11)$. Repeat distances and angles are measured from the central carbon (C12) using Mercury. ${ }^{53}$ For AH-B vs $\mathrm{MH}$ the matching molecules are highlighted in red.

To understand the susceptibility of the crystal surface to hydration this packing similarity assessment can be expanded to consider external crystal faces. The predicted growth morphologies for the various anhydrous forms are presented in Figure 8 and show reasonable agreement with those observed experimentally (see SEM images, Figure 2). For AH-C similarity with the $\mathrm{MH}$ 
was found to be present on the dominant morphological faces, $\{002\}$. In AH-C the $\{002\}$ faces represent $60 \%$ of the total facet area in the calculated morphology (Figure 8c). Given that the form was crystallised from a polar solvent, we expect the triazole functionality to dominate the chemistry of the surface. On this surface, conversion of the hydrogen bonding network of AH-C to that of the MH may be readily achieved via some surface expansion accompanied with the incorporation of the water.

For AH-A the similarity to the MH structure was found within the $\{111\}$ faces. However, these faces represent only $6 \%$ of the total predicted crystal morphology (Figure 8a) and they were not observed in the experimental morphology (Figure 9) (see section 2 of the Supporting Information for full indexing of AH-A and a new crystal structure determination at 296K). The localised similarity found between $\mathrm{AH}-\mathrm{B}$ and the $\mathrm{MH}$ is predicted to be within an internal plane. Breakage of the AH-A and AH-B crystals during grinding would be consistent with exposure of the $\{111\}$ planes of AH-A and $\{200\}$ planes of AH-B to the surface.
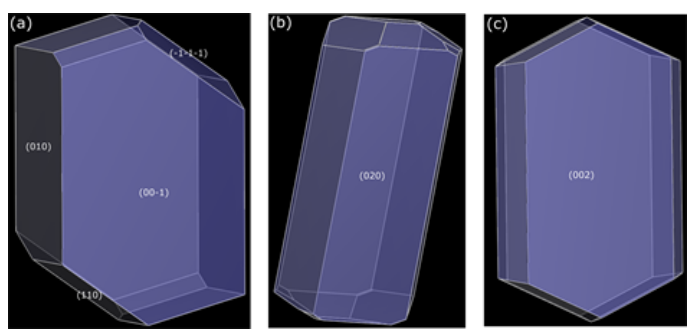

Figure 8 Predicted growth morphologies of (a) AH-A, (b) AH-B and (c) AH-C.

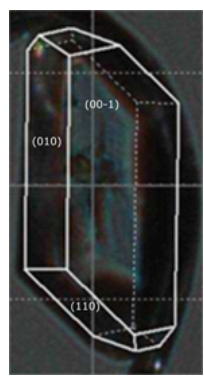

Figure 9 Face indexing of $\mathrm{AH}-\mathrm{A}$

\section{DISCUSSION}

We have performed some experimental hydration studies on three anhydrous polymorphs of fluconazole (AH-A, AH-B and $\mathrm{AH}-\mathrm{C})$ at 54.5 and $75.3 \% \mathrm{RH}$. Despite the RH value being above the critical water activities for all polymorphs, hydration was not observed at $54.5 \% \mathrm{RH}$ unless the system was activated by seed addition or grinding. At $75.3 \% \mathrm{RH}$, hydration was observed most significantly for $\mathrm{AH}-\mathrm{C}$, then $\mathrm{AH}-\mathrm{A}$ and only marginally for $\mathrm{AH}-$ $B$. The sigmoidal shape of the hydration isotherms reveals an initial induction period, possibly governed by the required nucleation of the $\mathrm{MH}$, followed by a growth period; ${ }^{54}$ this was particularly evident for AH-A and AH-C (Figure 3). Hydration slows towards the end; it can be presumed that this is because hydrating zones start to overlap.

Seeding or grinding of the samples considerably accelerated the hydration process for all forms. At $75.3 \% \mathrm{RH}$ the kinetics of hydration for AH-A closely mirrors that of AH-C, with AH-B becoming considerably more susceptible to hydration. Most interestingly, both the seeding and the grinding seem to eliminate the induction period required prior to hydration of $\mathrm{AH}-\mathrm{A}$ and $\mathrm{AH}-\mathrm{B}$. Thus, both crystal size reduction or the presence of MH crystals allow for a much more facile nucleation of the hydrate on the surface of the anhydrous crystals. Additionally, the enhanced slopes of the hydration curves, observed with seeding and grinding, suggests different propagation rates once nucleation has occurred, although again AH-B behaves differently with its rate remaining relatively low.

The accelerating impact of crystal size reduction underlines the importance of crystal surfaces in the nucleation process; higher surface areas offering greater probability of a nucleation event. The precise mechanism of such an event is however, more difficult to visualise. One potential route might be condensation of water on the surfaces facilitating a solution mediated pathway. However, this seems less likely since the anhydrous forms of fluconazole were found to be non-hygroscopic (see section 5.5 of the Supporting Information). For $\mathrm{AH}-\mathrm{A}$ and $\mathrm{AH}-\mathrm{B}$, even estimating a low surface area, the water content at $75.3 \% \mathrm{RH}$ is not sufficient to form a monolayer coverage of water on the crystal surface. This leads us to explore more fully potential solid-state processes which might be possible.

To aid the discussion of the impact of crystal structure on the hydration kinetics of the different polymorphs, we have summarised the results of our kinetic studies, structural analysis and energy calculations in Table 8 .

Clearly, at a basic level the hydration rates are concomitant with the level of similarity between the anhydrous and hydrated forms. The conformational and packing similarity found between the $\mathrm{AH}-\mathrm{C}$ and $\mathrm{MH}$ structures is consistent with $\mathrm{AH}-\mathrm{C}$ demonstrating the greater ease of hydration. AH-A has $2 \mathrm{D}$ similarity with the $\mathrm{MH}$, this does not extend in three dimensions without movement of adjacent molecular layers. Interestingly striations are seen within the crystals following hydration of AH-A, (Figure 10b) suggesting a degree of shear in the crystal during hydration. The direction of these striations is consistent with movement aligned to the $\{111\}$ planes. The conformational and relatively more modest packing similarity found between $\mathrm{AH}-\mathrm{A}$ and the $\mathrm{MH}$ is in line with the intermediate hydration behaviour of $\mathrm{AH}-\mathrm{A}$.

The lack of conformational similarity and only localised packing similarity between the $\mathrm{AH}-\mathrm{B}$ and $\mathrm{MH}$ structures provides a plausible explanation for the kinetic stability of AH-B to hydration. During hydration the molecular conformation, packing and hydrogen bonding pattern of the anhydrous form will need to change to match that of the hydrate. Thus, it seems reasonable that a closer structural similarity with the $\mathrm{MH}$, would facilitate an easier hydration process. The fact that AH-B has the smaller particle size (Figure 2) yet demonstrates the greater kinetic barrier to hydration, shows that the hydration rate cannot be purely related to surface area and particle size; molecular conformation and packing can also be influential.

Looking at the overall thermodynamic drive, we observe a correlation between the ease of hydration and the forms relative order of stability (Table 8 ). Thus, the least stable form, AH-C, hydrates faster than the intermediate form, $\mathrm{AH}-\mathrm{A}$, which also hydrates faster than the stable form, AH-B $\left(\Delta \mathrm{H}_{\text {form }}\right.$ in Table 8$)$.

Considering other energetic factors which may be controlling the kinetics of hydration: a) the highest energy barrier required for conformational conversion and b) the absolute value of the attachment energy for the softest crystal plane (lowest attachment energies). The first value relates to the maximum energy barrier required to convert the conformation of the anhydrous form to the conformation of the hydrate. This conformational energy barrier is just $\sim 11 \mathrm{~kJ} / \mathrm{mol}$ for AH-A and C but $29 \mathrm{~kJ} / \mathrm{mol}$ for AH-B (Table $8)$. The second value relates to the quantification of the softest 
plane in the crystal structure. Attachment energies have been shown to correlate with the kinetics of solvate formation for theophylline. ${ }^{55}$ Softer planes may allow an easier breakage of crystals or diffusion of solvent into the crystal structure to produce the hydration process. We note that microscopic images of our samples, after the hydration process reveal only small changes in the morphologies upon hydration. The morphologies remain very well defined, (Figure 10). Examination of the hydrated crystals, between crossed polarising filters, confirmed that the hydration process has completed in a single-crystal to single-crystal manner.
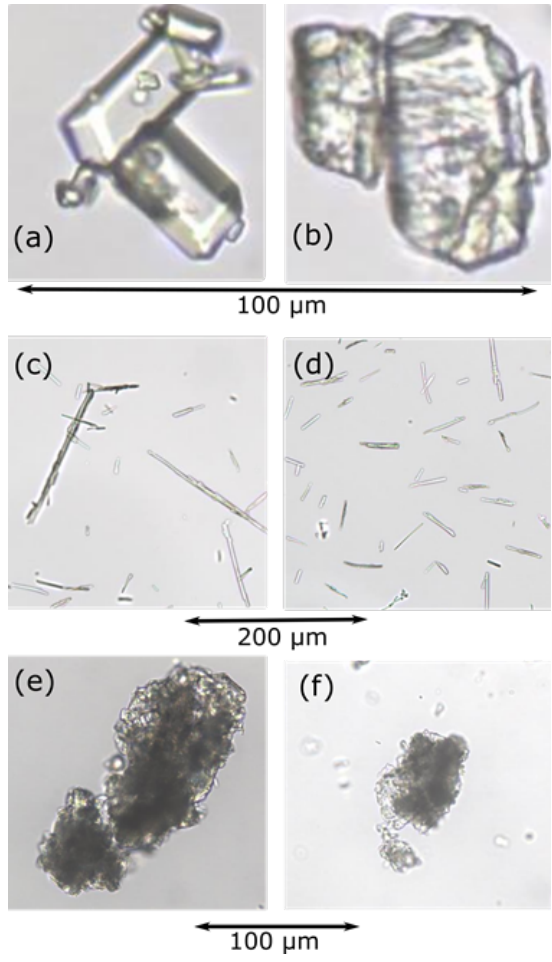

Figure 10 Photomicrographs taken to compare the physical appearance before and after hydration at $75 \% \mathrm{RH}$. (a) AH-A and (b) $\mathrm{MH}$ formed from hydration of $\mathrm{AH}-\mathrm{A}$. (c) $\mathrm{AH}-\mathrm{B}$ and (d) $\mathrm{MH}$ formed from hydration of AH-B when seeded with MH. (e) AH-C and (f) $\mathrm{MH}$ formed from hydration of $\mathrm{AH}-\mathrm{C}$.

Thus, we expect that polymorphs with softer planes would have faster kinetics of hydration since diffusion of the water into the structure would be more facile. These values are reported in Table 8. AH-C has the softest plane (smallest $-\mathrm{E}_{\text {att }}$ value) followed by $\mathrm{AH}-\mathrm{B}$ and $\mathrm{AH}-\mathrm{A}$. In this case, the values do not correlate with the kinetics because conformational changes are not accounted for in the attachment energies alone. We then calculate the overall kinetic energy barrier as the sum of the absolute value of the attachment energy plus the conformational energy barrier. This overall value is calculated to be 43,56 and $31 \mathrm{~kJ} / \mathrm{mol}$ for $\mathrm{AH}-\mathrm{A}, \mathrm{B}$ and $\mathrm{C}$ respectively and correlates very well with our observed kinetics of hydration of our original crystals. We notice, however, that the conformational changes required may be much more energetically costly within the crystal lattice, especially for those required for the AH-B form, where significant geometrical changes are required. Our gas-phase (or water) calculations combined with the attachment energies, however, are a convenient approximation. On grinding the crystals, the diffusion control of hydration becomes less dominant and the kinetics become controlled by the conformational energy barrier. Thus, on grinding both the AH-A and $\mathrm{AH}-\mathrm{C}$ show almost identical behaviour.

\section{CONCLUSIONS}

We have studied the hydration kinetics of three anhydrous forms of fluconazole: $\mathrm{AH}-\mathrm{A}, \mathrm{AH}-\mathrm{B}$ and $\mathrm{AH}-\mathrm{C}$. AH-B was found to demonstrate the greater kinetic barrier to hydration than $\mathrm{AH}-\mathrm{A}$ or AH-C. These kinetic studies, combined with a crystal packing, molecular conformational similarity analysis and energy calculations have revealed some important conclusions. Firstly, experiments showed that the hydration rates of ground and seeded (with $\mathrm{MH})$ samples are significantly increased relative to the ascrystallised materials. In the case of grinding considerable impact on the average size of the anhydrous crystals is evident while the crystallinity of the forms is maintained (neither pXRD nor DSC analysis show evidence of detectible amorphisation). These observations are accompanied by changes in the hydration profiles (the shape of the conversion-time curves) and suggest that three processes may be controlling the kinetics of hydration: a) diffusion of water inside the crystal lattice, b) nucleation of the monohydrate at crystal surfaces and c) growth of the monohydrate until full conversion is attained. The first two processes may be clearly influenced by grinding and seeding whilst growth may be more related to water diffusion and the similarity between the anhydrous forms and the $\mathrm{MH}$.

A comparison of the crystal packing and molecular conformations between the anhydrous forms and the $\mathrm{MH}$ revealed that $\mathrm{AH}-\mathrm{C}$ has the closest degree of similarity to the $\mathrm{MH}$ followed by $\mathrm{AH}-\mathrm{A}$ and AH-B. This correlates well with the observed relative hydration kinetics. Calculation of conformational similarities and energy barriers revealed that, when compared to $\mathrm{AH}-\mathrm{A}$ and $\mathrm{AH}-$ $\mathrm{C}$, the $\mathrm{AH}-\mathrm{B}$ conformation has to cross many more and higher energy barriers to convert to the $\mathrm{MH}$ conformation. This is consistent with the fact that AH-B shows the slowest hydration rate. The attachment energy values for the different planes in the various forms suggest which anhydrous form will be easier to break upon grinding and indicate the ease of water diffusion into the lattice. It was found that the combination of conformational and packing differences provide an overall kinetic energy barrier to hydration of AH-A, AH-B and AH-C. The values of this energy barrier correlate very well with the observed hydration kinetics.

In summary the hydration behaviour of $\mathrm{AH}-\mathrm{A}, \mathrm{AH}-\mathrm{B}$ and $\mathrm{AH}-$ $\mathrm{C}$ is aligned with their conformational and packing similarities relative to the MH structure. Surface similarity may be required for nucleation whereas a higher level of packing similarity allows for growth of the hydrate. Where there is little surface similarity or structural similarity, as with $\mathrm{AH}-\mathrm{B}$, there is a greater level of kinetic stability.

\section{ASSOCIATED CONTENT}

\section{Supporting Information}

A new crystal structure for AH-A at $296 \mathrm{~K}$ including crystallographic information and crystal indexing (CCDC Deposition Number 1951951). Form identification by pXRD for crystallised solid forms. Determination of the critical water activity (slurry method). Physicochemical properties for each polymorph including, TGA, DSC scanning electron microscopy images (where not included in manuscript). Hygroscopicity of anhydrous polymorphs. Hydration of anhydrous forms; sample weight taken during a six months exposure at 54.5 and $75.3 \% \mathrm{RH}$ with form identification for final samples. Environmental pXRD on AH-A and $\mathrm{AH}-\mathrm{C}$ at $90 \% \mathrm{RH}$ and $25{ }^{\circ} \mathrm{C}$. Adjustment and conformer energies for the monohydrate and the three polymorphs studied.

The Supporting Information is available free of charge on the ACS Publications website. 
Table 8 Summary of hydration kinetics, structural similarity and energetics analysis for AH-A, AH-B and AH-C in regard to the monohydrate.

\begin{tabular}{|c|c|c|c|c|}
\hline & & \multicolumn{3}{|l|}{ Anhydrous Forms } \\
\hline & & AH-A & AH-B & AH-C \\
\hline \multirow{2}{*}{$\begin{array}{l}\text { Experimental } \\
\text { Hydration Kinetics }\end{array}$} & $\begin{array}{l}\text { Hydration Rate ( } \alpha \text { /day) } \\
75 \% \text { RH, as cryst. }\end{array}$ & 0.0109 & 0.0008 & 0.0473 \\
\hline & $\begin{array}{l}\text { Hydration Rate ( } \alpha / \text { day) } \\
75 \% \text { RH, ground. }\end{array}$ & 0.1329 & 0.0048 & 0.1152 \\
\hline \multirow{4}{*}{ Structural Similarity } & Conformational Similarity & Similar & Very Different & Similar \\
\hline & $\begin{array}{l}\text { Required Conformational Rota- } \\
\text { tions }\end{array}$ & $\mathrm{OH}$ by $\sim 100^{\circ}$ & $\begin{array}{l}\text { triazole by } \sim 170^{\circ} \\
\mathrm{OCH}-\mathrm{CH}_{2} \text { by } \sim 125^{\circ} \\
\mathrm{OH} \text { by } \sim 100^{\circ}\end{array}$ & $\mathrm{OH}$ by $\sim 100^{\circ}$ \\
\hline & Packing Similarity & 2D similarity, dimers & Localised & 3D similarity \\
\hline & Surface Similarity & None & None & Dominant face \\
\hline $\begin{array}{l}\text { Energetics } \\
\text { Thermodynamics }\end{array}$ & $\Delta H_{\text {form }}(\mathrm{kJ} / \mathrm{mol})\left(\mathrm{T}=138-139^{\circ} \mathrm{C}\right)$ & 2.4 & 0.0 & 3.6 \\
\hline \multirow{3}{*}{$\begin{array}{l}\text { Energetics } \\
\text { Kinetics }\end{array}$} & $\begin{array}{l}\text { Conformational Energy } \\
\text { Barrier (kJ/mol) }\end{array}$ & 10.7 & 29.0 & 10.7 \\
\hline & $-E_{\text {att }}$ Softest hkl plane $(\mathrm{kJ} / \mathrm{mol})$ & $32.9 *$ & $27.0 *$ & $19.9 *$ \\
\hline & $\begin{array}{l}\text { Overall Energy Barrier } \\
(\mathrm{kJ} / \mathrm{mol})^{\S}\end{array}$ & 42.6 & 56.0 & 30.6 \\
\hline
\end{tabular}

* Those being the $\{001\},\{020\}$ and $\{002\}$ for AH-A, AH-B and AH-C respectively. ${ }^{\S}$ This is calculated as the sum of the conformational energy barrier and the $-\mathrm{E}_{\text {att }}$ of the softest plane.

\section{AUTHOR INFORMATION}

\section{Corresponding Author}

*Address: Patricia Basford, Medicinal Sciences, Pfizer R\&D UK Ltd, Sandwich, CT13 9NJ (UK). Email: pat.basford@pfizer.com Tel: +44(0)1304 643771 .

*Address: Aurora J. Cruz-Cabeza, School of Chemical Engineering and Analytical Science, University of Manchester, Manchester, M13 9PL (UK). Email: aurora.cruzcabeza@manchester.ac.uk Tel:+44(0)161306 8851 .

\section{Author Contributions}

$\mathrm{PAB}$ has designed and executed most experiments as well as major contributions to the writing of the manuscript. KRB and MC have contributed crystallography and SEM imaging expertise respectively. AJCC has contributed with computational expertise, project design discussions and manuscript writing. RD and RJD have contributed with work design discussions and manuscript revision.

\section{Notes}

The authors declare no competing financial interests.

\section{ACKNOWLEDGMENT}

We thank Kieran Baker for his assistance during crystallisation of the fluconazole forms and sample preparation during determination of the critical water activity. We thank Harriet Morgan (BA) for the TOC and abstract graphic. PB thanks Pfizer for materials, use of their equipment, laboratories and funding.

\section{REFERENCES}

1. Hilfiker, R. B., F.; von Raumer, M. , Polymorphism in the Pharmaceutical Industry. Wiley-VCH: Germany: 2007.
2. Bernstein, J., Polymorphism in Molecular Crystals. Clarendon Press: Oxford: 2002.

3. Brittain, H. G. M., K. R.; Boerrigter, S. X. M., Polymorphism in Pharmaceutical Solids. Informa Healthcare: New York, London,: 2009; Vol. 192.

4. Haleblian, J. K., Characterization of habits and crystalline modification of solids and their pharmaceutical applications. J. Pharm. Sci. 1975, 64 (8), 1269-88.

5. Cruz-Cabeza, A. J.; Reutzel-Edens, S. M.; Bernstein, J., Facts and fictions about polymorphism. Chem Soc Rev 2015, 44 (23), 8619-35.

6. Vippagunta, S. R.; Brittain, H. G.; Grant, D. J. W., Crystalline solids. Adv. Drug Delivery Rev. 2001, 48 (1), 3-26.

7. Shefter, E.; Higuchi, T., Dissolution behavior of crystalline solvated and nonsolvated forms of some pharmaceuticals. J. Pharm. Sci. 1963, 52 (8), 781-91.

8. Guidance for Industry: Pharmaceutical Solid Polymorphism. FDA, Ed. 2007; pp 1-10.

9. Byrn, S.; Pfeiffer, R.; Ganey, M.; Hoiberg, C.; Poochikian, G., Pharmaceutical solids: a strategic approach to regulatory considerations. Pharm. Res. 1995, 12 (7), 945-54.

10. Griesser, U. J., The importance of solvates. Polymorphism in the Pharmaceutical Industry. Wiley-VCH Verlag GmbH \& Co.: 2006.

11. Wikström, H.; Rantanen, J.; Gift, A. D.; Taylor, L. S., Toward an understanding of the factors influencing anhydrate-to-hydrate transformation kinetics in aqueous environments. Cryst. Growth Des. 2008, 8 (8), 2684-2693.

12. Zhu, H.; Grant, D. J. W., Influence of water activity in organic solvent + water mixtures on the nature of the crystallizing drug phase. 2 . Ampicillin. Int. J. Pharm. 1996, 139 (1,2), 33-43.

13. Zhu, H.; Yuen, C.; Grant, D. J. W., Influence of water activity in organic solvent + water mixtures on the nature of the crystallizing drug phase. 1. Theophylline. Int. J. Pharm. 1996, 135 (1,2), 151-160.

14. Zafarani-Moattar, M. T.; Davoodi, S., Water Activity Measurement for Alanine + Dipotassium Oxalate + Water and the Corresponding Binary Solutions at Different Temperatures. J. Chem. Eng. Data 2010, 55 (11), 5219-5224.

15. Krzyzaniak, J. F., Thermodynamic phase boundary for Caffeine anhydrate and hydrate. 
16. Ravikiran, A.; Arthanareeswari, M.; Kamaraj, P.; Praveen, C.; Pavan, K. V., Dehydration kinetics of sibutramine hydrochloride monohydrate. Chem. Sci. Trans. 2013, 2 (S1), S288-S294, 7 pp.

17. Sheng, J.; Venkatesh, G. M.; Duddu, S. P.; Grant, D. J. W., Dehydration Behavior of Eprosartan Mesylate Dihydrate. J. Pharm. Sci. 1999, 88 (10), 1021-1029.

18. Sheth, A. R.; Zhou, D.; Muller, F. X.; Grant, D. J. W., Dehydration kinetics of piroxicam monohydrate and relationship to lattice energy and structure. J. Pharm. Sci. 2004, 93 (12), 3013-3026.

19. Braun, D. E.; Griesser, U. J., Stoichiometric and Nonstoichiometric Hydrates of Brucine. Cryst. Growth Des. 2016, 16 (10), 6111-6121.

20. Stephenson, G. A.; Groleau, E. G.; Kleemann, R. L.; Xu, W.; Rigsbee, D. R., Formation of Isomorphic Desolvates: Creating a Molecular Vacuum. J. Pharm. Sci. 1998, 87 (5), 536-542.

21. Griesser, U. J.; Burger, A., The effect of water vapor pressure on desolvation kinetics of caffeine 4/5-hydrate. Int. J. Pharm. 1995, 120 (1), 83-93.

22. Hedoux, A.; Paccou, L.; Derollez, P.; Guinet, Y., Dehydration mechanism of caffeine hydrate and structural description of driven metastable anhydrates analyzed by micro Raman spectroscopy. Int. J. Pharm. (Amsterdam, Neth.) 2015, 486 (1-2), 331-338.

23. Liu, C.; Dang, L.; Tong, Y.; Wei, H., Influence of Polymorphs on the Transformation Water Activity of Theophylline. Ind. Eng. Chem. Res. 2013, 52 (42), 14979-14983.

24. Gillon, A. L.; Davey, R. J.; Storey, R.; Feeder, N.; Nichols, G.; Dent, G.; Apperley, D. C., Solid State Dehydration Processes: Mechanism of Water Loss from Crystalline Inosine Dihydrate. J. Phys. Chem. B 2005 , 109 (11), 5341-5347.

25. Burger, A.; Griesser, U. J., The polymorphic drug substances of the European Pharmacopoeia. Part 7. Physical stability, hygroscopicity, and solubility of succinylsulfathiazole crystal forms. Eur. J. Pharm. Biopharm. 1991, 37 (2), 118-24.

26. Alkhamis, K. A.; Obaidat, A. A.; Nuseirat, A. F., Solid-state characterization of fluconazole. Pharm Dev Technol 2002, 7 (4), 491-503.

27. Desai, S. R.; Shaikh, M. M.; Dharwadkar, S. R., Thermoanalytical study of polymorphic transformation in Fluconazole drug. Thermochim. Acta 2003, 399 (1-2), 81-89.

28. Park, H. J.; Kim, M.-S.; Lee, S.; Kim, J.-S.; Woo, J.-S.; Park, J.-S.; Hwang, S.-J., Recrystallization of fluconazole using the supercritical antisolvent (SAS) process. Int. J. Pharm. 2007, 328 (2), 152-160.

29. Park, H. J.; Kim, M.-S.; Kim, J.-S.; Cho, W.; Park, J.; Cha, K.H.; Kang, Y.-S.; Hwang, S.-J., Solid-state carbon NMR characterization and investigation of intrinsic dissolution behavior of fluconazole polymorphs, anhydrate forms I and II. Chem. Pharm. Bull. 2010, 58 (9), 1243 1247.

30. Karanam, M.; Dev, S.; Choudhury, A. R., New Polymorphs of Fluconazole: Results from Cocrystallization Experiments. Crystal Growth \& Design 2012, 12 (1), 240-252.

31. Gorkovenko, E. A.; Kichanov, S. E.; Kozlenko, D. P.; Belushkin, A. V.; Wasicki, J.; Nawrocik, W.; Mielcarek, J.; Dubrovinsky, L. S.; Lathe, C.; Savenko, B. N., The Pressure-Induced Polymorphic Transformations in Fluconazole. J. Pharm. Sci. 2015, 104 (12), 4164-4169.

32. Caira, M. R.; Alkhamis, K. A.; Obaidat, R. M., Preparation and Crystal Characterization of a Polymorph, a Monohydrate, and an Ethyl Acetate Solvate of the Antifungal Fluconazole. Journal of Pharmaceutical Sciences 2004, 93 (3), 601-611.

33. Alkhamis, K. A.; Salem, M. S.; Obaidat, R. M., Comparison between dehydration and desolvation kinetics of fluconazole monohydrate and fluconazole ethylacetate solvate using three different methods. $J$ Pharm Sci 2006, 95 (4), 859-70.

34. Groom, C. R.; Bruno, I. J.; Lightfoot, M. P.; Ward, S. C., The Cambridge Structural Database. Acta Crystallographica Section B 2016 , 72 (2), 171-179.
35. Plus, A., Aspen Plus user guide. Aspen Technology Limited, Cambridge, Massachusetts, United States 2003.

36. Renon, H.; Prausnitz, J. M., Local compositions in thermodynamic excess functions for liquid mixtures. AIChE Journal 1968, 14 (1), $135-144$.

37. Nyqvist, H., Saturated salt solutions for maintaining specified relative humidities. Int J Pharm Tech Prod Mfr 1983, 4 (2), 47-48.

38. LINK, 1.05.8; Linkam Scientific Instruments Ltd, Unit 8, Epsom Downs Metro Centre, Tadworth, , Surrey, KT20 5LR, UK: 2016.

39. Cruz-Cabeza, A. J.; Bernstein, J., Conformational Polymorphism. Chemical Reviews 2014, 114 (4), 2170-2191.

40. Grimme, S., Semiempirical GGA-type density functional constructed with a long-range dispersion correction. J. Comp. Chem. 2006, (27), 1787-1799.

41. M. J. Turner, J. J. M., S. K. Wolff, D. J. Grimwood, P. R. Spackman, D. Jayatilaka and M. A. Spackman CrystalExplorer 17, University of Western Australia, 2017.

42. Turner, M. J.; Grabowsky, S.; Jayatilaka, D.; Spackman, M. A., Accurate and Efficient Model Energies for Exploring Intermolecular Interactions in Molecular Crystals. The Journal of Physical Chemistry Letters 2014, 5 (24), 4249-4255.

43. Mackenzie, C. F.; Spackman, P. R.; Jayatilaka, D.; Spackman, M. A., CrystalExplorer model energies and energy frameworks: extension to metal coordination compounds, organic salts, solvates and open-shell systems. IUCrJ 2017, 4 (5), 575-587.

44. Materials Studio 2018, 18.1.0.2017; BIOVIA Dassauly Systèmes: 2018 .

45. SmartSEM, 5.06; Carl Zeiss Microscopy Ltd.: 2019

46. TRIOS, 4.3.1; TA Instruments, 159 Lukens Drive, New Castle, DE 19720, USA: 2018.

47. DIFFRAC.EVA, v4.2.1.10; Bruker AXS GmbH, Karlsruhe, Germany: 2016.

48. Grant, D. J. W.; York, P., Entropy of processing: a new quantity for comparing the solid state disorder of pharmaceutical materials. International journal of pharmaceutics 1986, 30 (2), 161-180.

49. Longuemard, P.; Jbilou, M.; Guyot-Hermann, A. M.; Guyot, J. C., Ground and native crystals: comparison of compression capacity and dissolution rate. International journal of pharmaceutics 1998, 170 (1), 5161

50. Gillon, A. L.; Feeder, N.; Davey, R. J.; Storey, R., Hydration in Molecular Crystals - A Cambridge Structural Database Analysis. Cryst. Growth Des. 2003, 3 (5), 663-673.

51. Motherwell, S.; Chisholm, J. A., COMPACK: a program for identifying crystal structure similarity using distances. Journal of Applied Crystallography 2005, 38 (1), 228-231.

52. Macrae, C. F.; Bruno, I. J.; Chisholm, J. A.; Edgington, P. R.; McCabe, P.; Pidcock, E.; Rodriguez-Monge, L.; Taylor, R.; van de Streek, J.; Wood, P. A., Mercury CSD 2.0 - new features for the visualization and investigation of crystal structures. Journal of Applied Crystallography 2008, 41 (2), 466-470.

53. Macrae, C. F.; Edgington, P. R.; McCabe, P.; Pidcock, E.; Shields, G. P.; Taylor, R.; Towler, M.; van de Streek, J., Mercury: visualization and analysis of crystal structures. Journal of Applied Crystallography 2006, 39 (3), 453-457.

54. Cardew, P. T.; Davey, R. J.; Ruddick, A. J., Kinetics of polymorphic solid-state transformations. J. Chem. Soc., Faraday Trans. 2 1984, 80 (6), 659-68.

55. Hasa, D.; Pastore, M.; Arhangelskis, M.; Gabriele, B.; CruzCabeza, A. J.; Rauber, G. S.; Bond, A. D.; Jones, W., On the kinetics of solvate formation through mechanochemistry. CrystEngComm 2019, 21 (13), 2097-2104 
The Impact of Crystal Structure and Molecular Conformation on the Hydration Kinetics of Fluconazole *Patricia A. Basford, Kevin R. Back, Michael Cram, Robert Docherty, Roger J. Davey and *Aurora J. Cruz-Cabeza.

\section{SYNOPSIS TOC}

Three polymorphs of fluconazole exhibit significantly different kinetic behaviour towards hydration. Here we demonstrate that conformational variations, seeding and particle size reduction all impact the hydration kinetics of the fluconazole polymorphs. Larger conformational changes seem to impact the hydration kinetics most significantly.

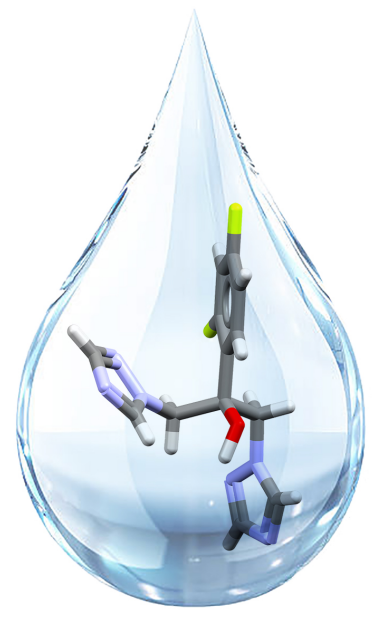

Please also use as Abstract graphic 